\title{
LA POLITICA DE JORNADA ÚNICA ESCOLAR: LOS REFERENTES Y LA EXPERIENCIA DE UNA INSTITUCIÓN EDUCATIVA DISTRITAL *
}

\section{The unique school day policy: the referents and the experience of a district educational institution}

Henry Bocanegra Acosta**

Adriana Patricia Huertas Bustos***

Recepción: 12 de junio de 2018. Aceptación: 07 de julio de 2018.

DOI: http://dx.doi.org/10.21017/Rev.Repub.2018.v25.a56

\section{RESUMEN}

Artículo producto de estudio sobre la política pública educativa de jornada única en los niveles de preescolar, básica y media. Esta investigación tuvo como objetivos valorar los lineamientos de la referida política pública y de sus principales desarrollos normativos legales y reglamentarios, así como también evaluar la experiencia de una institución educativa distrital frente a estos temas, mediante la aplicación de un instrumento construido y validado por criterio de expertos. El problema de investigación se concreta en unas preguntas problematizadoras: ¿Desde qué referentes de orden político, discursivo y jurídico se ha pretendido implementar la política educativa de jornada única escolar en Colombia y qué tensiones se pudieron generar en ese

* Artículo en colaboración, producto del proyecto de investigación: La jornada única escolar en Bogotá: la experiencia de una institución educativa distrital -IED, desarrollado en el marco de la maestría en educación de la Universidad Antonio Nariño, Bogotá D. C. 2018.

** Doctor en Sociología Jurídica e Instituciones Políticas, de la Universidad Externado de Colombia. Especialista y magíster en Administración Pública, Escuela Superior de Administración Pública (ESAP). Abogado de la Universidad Libre. Licenciado en Ciencias de la Educación -especialidad sociales-. Maestrante en Educación de la Universidad Antonio Nariño. Docente investigador de la Universidad Libre, Grupo de Investigaciones Socio Jurídicas (GISJ); docente de la Corporación Universitaria Republicana. Investigador asociado Colciencias.

*** Doctora en educación y magíster en Tecnologías de la Información Aplicadas a la Educación, de la Universidad Pedagógica Nacional, UPN (Bogotá D. C.). Licenciada en Química. Directora Investigación (UDCII), Facultad de Educación de la Universidad Antonio Nariño. Investigadora asociada Colciencias. 
proceso? y ¿Cómo se percibe por parte de los estamentos básicos de una institución educativa oficial de los niveles de preescolar, básica y media el proceso de implementación de la jornada única escolar? Es un trabajo que se desarrolló desde dos perspectivas metodológicas: una primera parte de carácter histórico documental y una segunda de orden cuantitativo que surge del análisis estadístico producto de la aplicación de una encuesta con 45 ítems de escala Likert. A partir de allí se pudo concluir que pese a los desarrollos jurídicos la jornada única como una acción de carácter pedagógico ha generado tensiones que han involucrado especialmente a los docentes, que cuestionan los procedimientos y las condiciones de implementación y ofrecen unas alternativas que permitan su desarrollo en términos de dignidad y pertinencia para las comunidades educativas.

Palabras clave: política educativa, jornada única escolar, currículo, convivencia escolar, jornada laboral docente, derecho a la educación.

\section{ABSTRACT}

Article product of study on the public educational policy of a single day at the preschool, basic and middle levels. The objective of this research was to assess the guidelines of the aforementioned public policy and its main legal and regulatory developments, as well as to evaluate the experience of a district educational institution regarding these issues, through the application of an instrument constructed and validated by criteria of experts. The research problem is concretized in some problematizing questions: From what political, discursive and juridical reference has been tried to implement the educational policy of a single school day in Colombia and what tensions could be generated in that process? And how is the process of implementing the single school day perceived by the basic levels of an official educational institution at the preschool, elementary and middle school levels? It is a work that was developed from two methodological perspectives, a first part of documentary historical character and a second one of quantitative order that arises from the statistical analysis product of the application of a survey with 45 Likert scale items. From there it was possible to conclude that despite the legal developments the single day as a pedagogical action has generated tensions that have involved teachers especially, who question the procedures and implementation conditions and offer alternatives that allow their development in terms of dignity and relevance for the educational communities.

Key Words: educational policy, single school day, curriculum, school life, teaching workday, right to education. 


\section{INTRODUCCIÓN}

La jornada única es un esquema de organización del tiempo escolar que se propone ampliar la permanencia de los educandos en el colegio, de seis a ocho horas, con unas condiciones de bienestar estudiantil y unos procesos curriculares socialmente pertinentes. Como tal, esta iniciativa ha comprometido la existencia de las dobles jornadas diurnas que por los problemas de cobertura experimentados a finales de la década de 1960 se les exigió asumir a las instituciones educativas, prestando el servicio educativo en una sola planta física, a dos comunidades estudiantiles distintas, en horarios diferentes: jornada mañana de $6: 30$ a. m. a 12:30 p. m., y jornada tarde de 12:45 p. m. a 6:45 p. m. En colegios con jornada nocturna se daba de tal forma que esta iniciara a las 6:30 p. m., para finalizar a las 10:00 p. m.

Retomar la jornada única, después de décadas donde predominaron las dobles y triples jornadas escolares, se ha constituido en un verdadero reto para todos los actores del proceso educativo en Colombia. El mismo término de jornada única adquiere un valor frente a una realidad que no se ha dado en otras latitudes: la existencia de dobles y triples jornadas en los establecimientos educativos de preescolar, básica y media, con todo lo que ello ha podido implicar en materia financiera para el Estado y deterioro de las plantas físicas, de los recursos didácticos y tecnológicos, de la calidad del servicio y de la formación de los educandos (Quintero, Munévar \& Munévar, 2015).

En los términos aludidos anteriormente podemos expresar que la jornada única en términos de una política pública sectorial significa una ampliación de la permanencia de los escolares en el establecimiento educativo y la disposición de desarrollar la jornada escolar predominantemente durante el periodo matutino. La norma que regula la jornada única en Colombia, Decreto 2105 de 2017, establece la definición en el artículo 2.3.3.6.1.3:

La Jornada Única establecida en el artículo 85 de la Ley 115 de 1994, modificado por el artículo 57 de la Ley 1753 de 2015, comprende el tiempo diario que dedica el establecimiento educativo oficial a sus estudiantes de básica y media en actividades académicas para el desarrollo de las áreas obligatorias y fundamentales y de las áreas o asignaturas optativas, y a los estudiantes de preescolar su desarrollo en los aspectos biológico, cognoscitivo, sicomotriz, socio afectivo y espiritual a través de experiencias de socialización pedagógicas y recreativas, así como el tiempo destinado a actividades de descanso pedagógico y alimentación de los estudiantes. El tiempo de la Jornada Única y su implementación se realizará según el plan de estudios definido por el Consejo Directivo y de acuerdo con las actividades señaladas por el Proyecto Educativo Institucional determinado por los establecimientos educativos, en 
ejercicio de la autonomía escolar definida en el artículo 77 de la Ley 115 de 1994 y sus normas reglamentarias. La Jornada Única se prestará en jornada diurna durante cinco (5) días a la semana y el horario escolar de esta jornada permitirá cumplir con el número de horas de dedicación a las actividades académicas definidas en el artículo 2.3.3.6.1.6 del presente Decreto.

Por su parte, el artículo 2.3.3.6.1.6 referido en la anterior disposición establece las horas semanales de duración de la Jornada Única: 20 para preescolar, 25 para básica primaria, y 35 para básica secundaria y media. Esta norma se expide por parte del gobierno bajo la consideración oficial de recoger las peticiones formuladas por la Fecode en el proceso de negociación colectiva que llevó a reformar el Decreto 1075 de 2015 para dar cumplimento, según los considerandos de la citada norma, a los numerales 6 a 8 del Acta de Acuerdos con esta organización sindical (Colombia. MEN, 2017).

La política pública de jornada única en Colombia se ha venido ejecutando en un contexto de dificultades de diverso género: presupuestales, laborales, de infraestructura y contratación pública, entre otros, en un asunto clave como el Plan de Alimentación Escolar (PAE) ${ }^{1}$, pero igualmente de resistencia de los principales actores del proceso educativo colombiano: los maestros, respecto a la hipotética o real incidencia pedagógica y laboral de la alusiva política pública sectorial ${ }^{2}$.

1 El PAE ha sido un programa cuestionado por el alto número de irregularidades en los procesos de contratación denunciados y sancionados por los órganos de vigilancia y control y las autoridades judiciales en cientos de entidades territoriales. El 19 de septiembre de 2018 el presidente de la República, Iván Duque Márquez, lanza el nuevo programa de alimentación escolar y le corresponde reconocer esta grave situación. Expresaba el mandatario que “ «El Programa de Alimentación Escolar como ustedes saben, ha sido seriamente cuestionado, porque se ha prestado para que haya colusión de contratistas, para que haya una malla de contratistas que se apodera de los recursos, para que muchos de ellos lo hagan a través de niños fantasma y con eso se quedan con recursos, otros se aprovechan de figuras como los convenios interadministrativos para generar abusos» (Colombia. Presidencia de la República, 2018).

2 La jornada única fue uno de los asuntos avocados en la Mesa de Negociaciones que se instaló para atender el conflicto laboral entre la organización sindical de los maestros del sector público colombiano y el gobierno nacional durante el primer semestre de 2017. MINISTERIO DE EDUCACIÓN NACIONAL - FEDERACIÓN COLOMBIANA DE TRABAJADORES DE LA EDUCACIÓN (FECODE). Acuerdos de la negociación pliego de peticiones radicado por la Federación el veintiocho (28) de febrero. 16 de junio de 2017, punto nro. 6: Jornada Única Escolar. En la parte introductoria el referido documento señala: «A los 16 días del mes de junio de 2017, el gobierno nacional, representado por la ministra de Educación Nacional, y la Federación Colombiana de Trabajadores de la Educación (Fecode), representada por los negociadores designados, celebraron, en el marco del Decreto 160 de 2014, los siguientes acuerdos que responden al pliego de peticiones radicado por la Federación el veintiocho (28) de febrero del presente año». 
Miguel Ángel Pardo Romero, presidente de la Asociación de Trabajadores y Trabajadoras de la Educación (ADE), hasta octubre de 2018, y actual integrante del Comité Ejecutivo de Fecode, hacía los siguientes planteamientos respecto a la política de jornada única:

En el caso de la imposición de las mal llamadas jornadas «únicas»o «extendidas», la ADE insiste en que son ilegales, indignas y sospechosamente improvisadas, ¿por qué? La SED ha procedido a avalar o presionar a los colegios para que implementen la mal llamada jornada única o la ilegítima jornada «extendida», sin existir condiciones dignas, ni sustentación académica, ni el obligado procedimiento que establece el artículo 15 del Decreto 1860 de 1994. Pese a que así lo establecen los Acuerdos Fecode-MEN, suscritos el 16 de junio de 2017, los cuales tienen carácter vinculante... Constituye una clara agresión a las niñas, niños y jóvenes y a sus derechos fundamentales, obligarlos a asistir una jornada «extendida» sin alimentación apropiada, insuficiente, inexistente o deteriorada, como también, sin restaurantes o cocinas escolares como lo exigen los protocolos nacionales o internacionales. A estas razones, se suma el hacinamiento que también produce el hecho de solo construir 30 de los 420 colegios necesarios para albergar a los 300.000 estudiantes que se encuentran en las jornadas de la tarde. Se sigue así generando problemas de salud desde edades tempranas de incalculables consecuencias... La SED ha procedido a desregularizar la jornada laboral de los docentes que es de 6 horas presenciales continuas y sus actos administrativos tienen ubicación en la jornada mañana o tarde. No existe competencia alguna ni de la Secretaría de Educación ni de las Direcciones Locales de Educación (DILE). Tampoco un acuerdo de «voluntades» entre rectores y docentes, está por encima de la normatividad vigente.

En el proceso de negociación con la ADE, la Secretaría de Educación de Bogotá reconoció que no habrá más recursos ni propios ni provenientes del Sistema General de Participaciones (SGP); sin embargo, aún mantiene la meta de pasar del 11\% a $64 \%$ en la implementación de la jornada única o extendida. Peor aún, el diario Portafolio del día 22 de junio de 2018 registró que el Congreso hundió el proyecto de reforma que buscaba que «esas partidas a las regiones aumentaran al menos la inflación, durante cada año». Entre menos recursos, la SED más niega el Estado social de derecho e induce más a los rectores, a los integrantes de «comités de gestión» o de los órganos de gobierno a apartarse de la ley, dejándolos expuestos a eventuales acciones jurídicas. No es la primera vez que lo advertimos (Pardo, 1 de julio de 2018).

La jornada única escolar ha exigido un reordenamiento institucional del sector y de las instituciones educativas no solo respecto a la ampliación, uso y control 
del tiempo escolar, sino en materia de manejo de los espacios y recursos, organización curricular, administración del personal docente y asignación de nuevas funciones que permita afrontar las nuevas realidades y exigencias que se derivan de su adopción institucional y los retos que ella (la jornada única) implica en materia de bienestar estudiantil, seguridad y convivencia escolar, atención y compromiso de los padres, madres y acudientes, pero fundamentalmente en la generación de procesos de innovación curricular y mejoramiento de la calidad docente y de los desempeños de los educandos. Las autoridades competentes han avanzado en la regulación jurídica conforme los debates o necesidades suscitadas en la implementación de la política. Inicialmente se expidieron unas normas recogidas o compiladas en el Decreto 1075 de 2015, Único Reglamentario del Sector Educación, en relación con la jornada única escolar (MEN, 2018). Con todo, las autoridades políticas nacionales ha planteado con suficiente claridad que «la política de implementación de la Jornada Única no es optativa, ni para las instituciones educativas ni para las Entidades Territoriales Certificadas, como responsables de la prestación del servicio educativo» (MEN, 2018, p. 13).

En el plano internacional la ampliación de la jornada escolar se ha percibido como una medida que ha tenido efectos positivos en el ámbito pedagógico (Martinic, 2015, p. 483) pero que a su vez ha impactado en otros ámbitos de la vida de las familias. En Chile, por ejemplo, la política pública de Jornada Escolar Completa (JEC) impulsada desde 1996, que involucró el aumento de un $30 \%$ sobre las horas de colegiatura diarias, sumando un total de 1.140 horas al año, para los estudiantes de colegio oficiales, complementariamente a los beneficios de orden pedagógico, puede haber tenido algún efecto sobre la calidad del empleo al que acceden las madres favorecidas: «aumento de la jornada escolar proporcionado por la JEC puede ser visto como una solución 'potencial' al acceso a empleos de mejor calidad para las madres de los alumnos abarcados por el programa» (Zamora, 2014, p. 3).

Según Holland (2012), la tendencia mundial de los gobiernos es incrementar la jornada escolar, sin la claridad suficiente frente al impacto de esta medida en los desempeños de los educandos y calidad del servicio. Paradójicamente, Corea del Sur obtiene un buen resultado tanto en tiempo como en aprendizaje; otros países como Italia y México dedican más horas a la enseñanza y sus resultados académicos no mejoran de manera considerable: realidad que afronta de la misma manera la América Latina. Asimismo en los Estados Unidos, algunos sectores han hecho un llamado a incrementar el tiempo de permanencia en las escuelas, argumentando que en promedio sus estudiantes tienen un mes menos de clase que sus congéneres de Corea del Sur, lo que se constituye en una desventaja (Holland, 2012). 


\section{PLANTEAMIENTO DEL PROBLEMA}

La educación entendida como derecho fundamental sufre una afectación cuando el Estado y la institución educativa no brindan las condiciones físicas y administrativas necesarias (tiempos, infraestructura, bienestar, seguridad y convivencia, recursos profesionales tecnológicos y didácticos) para enseñar y aprender conforme al proyecto educativo institucional. Resulta pertinente estudiar la realidad de los ambientes y contextos escolares, de las formas en que se asume la organización de las instituciones educativas, pero especialmente que verifiquen sobre el sentido, el alcance y las posibilidades de la jornada única escolar y de la regulación jurídica desde la cual se ha pretendido materializarla en Colombia.

La adopción de la jornada única implica la realización de ajustes institucionales de los colegios, que generan tensiones. Se trastoca la cultura sobre el uso de tiempo escolar, la jornada laboral de los docentes y directivos docentes, las rutinas y hábitos alimenticios, las reglas de juego para el uso de áreas comunes y espacios institucionales. Un cambio en la jornada escolar impacta no solo a los actores directos del proceso educativo (maestros, estudiantes y profesores); a las madres y padres de familia se les puede perturbar la vida (Martinic, 2015, p. 485).

De otra parte, la jornada escolar colombiana ha tomado diversas interpretaciones, enfoques o perspectivas en Bogotá y en otras entidades territoriales; variedad de denominaciones, en concordancia con las interpretaciones o posibilidades de implementación que las mismas autoridades político-administrativas enfrentan o tienen: jornada única escolar, jornada extendida, jornada complementaria y 40X40, todas implican aumento del tiempo de permanencia, en algunos casos manteniendo las dobles y triples jornadas con programas complementarios por fuera de las instalaciones del colegio y con entidades privadas, cajas de compensación, ONG, o entidades públicas que atienden programas artísticos, de recreación o deportes.

En este sentido, el uso del tiempo escolar, las directrices políticas y jurídicas sobre la jornada escolar, la disposición de recursos, el tipo de regulaciones laborales, los niveles de autonomía escolar y los propios entornos escolares inciden sobre los procesos curriculares y convivenciales de los colegios, como también afectan la calidad del servicio y el cumplimiento de la función social que le corresponde a la escuela colombiana frente a los derechos, las garantías y las libertades de 8.500.000 estudiantes, 322.473 maestros del sector oficial, según estimativo que hace Rivas (2017), y por supuesto de las instituciones, estudiantes, docentes y empresarios vinculados a la educación privada. 
Teniendo en cuenta los argumentos anteriormente planteados, este ejercicio investigativo estuvo orientado al abordaje de un problema de investigación que se expresa a partir de unas preguntas problematizadoras:

1. ¿Desde qué referentes de orden político, discursivo y jurídico se ha pretendido implementar la política educativa de jornada única escolar en Colombia y qué tensiones se pudieron generar en ese proceso?

2. ¿Cómo se percibe por parte de los estamentos básicos de una institución educativa oficial de los niveles de preescolar, básica y media el proceso de implementación de la jornada única escolar?

\section{REFERENTES SOBRE LA POLÍTICA DE JORNADA ÚNICA EN COLOMBIA}

\subsection{Algunos antecedentes investigativos en Colombia}

El tema de la jornada única representa en el período actual un «campo de confrontaciones», donde se expresan distintas posturas frente a su alcance e incidencia sobre los ambientes escolares y las posibilidades para mejorar el aprendizaje de los niños, niñas y jóvenes; donde se formulan disímiles planteamientos sobre la pertinencia de los dispositivos legales y de política pública desde los cuales se intenta concretar las metas propuestas. Algunos trabajos académicos han contribuido a dimensionar el problema de la relación entre el tiempo de permanencia de los escolares y la calidad educativa; en este sentido, Bonilla (2011) logró algunos adelantos investigativos que han fundamentado algunas propuestas de ajuste institucional:

...menos del $18 \%$ de los jóvenes colombianos asisten a clase durante la jornada completa. Pese a la creciente evidencia internacional de que las medias jornadas escolares, reducen la calidad de la educación y aumenta la exposición a distintos factores de riesgo, y que la calidad de la educación es uno de los principales determinantes del crecimiento económico y del desarrollo, resulta preocupante ver que la jornada escolar es un tema que apenas ocupa un lugar marginal en el debate sobre la educación en el país. Peor aún, el argumento central para preservar este esquema de doble jornada sigue siendo el mismo desde hace casi cincuenta años: hay serios problemas de cobertura y los recursos son insuficientes (Bonilla, 2011, p. 1).

Otros trabajos han aportado en la comprensión de la política educativa de jornada única en algunos contextos específicos, como el trabajo de Gallego (2008) sobre el programa de jornada complementaria ejecutado en seis munici- 
pios de Caldas, pero con un principal escenario: el municipio de Supía de ese departamento. La investigación reconoció los niveles de participación, los cambios actitudinales en los estudiantes atribuibles al programa y los aportes que se dieron en su formación personal en aspectos como la identidad, la convivencia, el respeto, el acatamiento de normas y la confianza, así como en su formación académica, derivados de la referida política pública (Gallego, 2008).

En este mismo sentido, el MEN (2013) publica los resultados de un estudio que evaluó la implementación de la jornada única en establecimientos educativos del sector rural; el Informe presenta algunos hallazgos importantes como: la necesidad de mejorar los espacios físicos, el financiamiento de la alimentación escolar y la creación de aulas especializadas que mejoren los aprendizajes. Los anteriores estudios dejan ver la necesidad de generar condiciones adecuadas que garanticen una jornada única apta para desarrollar aprendizajes efectivos.

\subsection{Derecho a la educación, tiempo escolar y calidad educativa}

La educación en cuanto es un derecho habilitante de otros derechos se convierte para muchas personas y comunidades en el único camino, posibilidad o alternativa para alcanzar la prosperidad individual y colectiva. El desarrollo de una nación estará garantizado en la medida que invierta suficientes recursos en la formación de capacidad humana. Los requerimientos de la producción económica, la convivencia y la seguridad ciudadana, entre otros asuntos, tienen en la educación un escenario imprescindible de realización y satisfacción.

Los sistemas educativos formales son un producto histórico de la modernidad y el capitalismo. Por su importancia estratégica, en el marco de necesidades económicas, políticas e ideológicas, la educación, la escuela y los maestros han sido objeto de una compleja regulación jurídica y de amplios instrumentos de control institucional y social; regulaciones e instrumentos que se modifican de acuerdo con la correlación de fuerzas en el ámbito político, el peso de las circunstancias o producto de movilizaciones sociales, pero igualmente que generan tensiones de diferente tipo y nivel; unas veces entre las comunidades educativas y las autoridades públicas; entre las facciones políticas que pugnan por el poder, o entre las organizaciones estudiantiles, que históricamente han luchado por una educación pública, gratuita y de calidad (Blanco, 2014, p. 140), las sindicales docentes y los poderes públicos frente al sentido y alcance de tal o cual política o desarrollo legal que se perciba que afecte el derecho a la educación o las condiciones para el ejercicio de la profesión docente.

En el mundo contemporáneo se reconoce política y culturalmente el valor y el poder de la educación para transformar las estructuras sociales y redimensionar 
las prácticas de vida, los procesos de enseñanza y de aprendizaje y, ciertamente, la constitución de las ciudadanías. La educación es entonces un derecho habilitante, pues permite la realización de todos los derechos humanos, en la construcción del conocimiento que hace posible la dignificación de la vida, y por ello es también un derecho civil, político, económico y cultural (Muñoz, 2011, p. 31).

En el marco de lo que exige el derecho internacional, el derecho interno y los propios planes de desarrollo, le corresponde al Estado ordenar la prestación del servicio educativo, garantizar el cumplimiento de una serie de principios: accesibilidad, asequibilidad, adaptabilidad y aceptabilidad (Organización de Naciones Unidas -ONU. Asamblea General, 1966, artículo 13), desde los cuales se evalúa el sentido, el alcance, la incidencia o el valor de la educación en cuanto derecho fundamental en un contexto socioeconómico nacional determinado.

El ordenar la educación implicó definir las reglas de juego y las condiciones para el funcionamiento de la escuela, con la disposición de los recursos materiales y humanos necesarios, la organización del trabajo y jornada laboral docente, la definición del horizonte institucional y el currículo, la disposición del tiempo de permanencia de los escolares. Es decir, estableciéndose la duración de la jornada escolar; los períodos de clase; los tiempos para la atención de padres, madres y acudientes; los tiempos para el consumo de alimentos, para el descanso y la recreación de los educandos y para el respectivo acompañamiento de los docentes.

El uso del tiempo en la escuela, especialmente el referido a la jornada escolar, en cuanto condición o elemento del currículo, ha sido objeto de análisis prácticos y ejercicios de teorización y conceptualización, seguramente por la relativa relevancia de este asunto en el concierto de necesidades de la escuela y de la formación de los educandos.

La organización del tiempo escolar y las condiciones espaciales determinan el conjunto de procesos y actividades que cotidianamente desarrolla la escuela. Todo está en función, condicionado y justificado desde el tiempo. Para Martinic (2015) la organización del tiempo escolar en la región continúa respondiendo a un concepto racional y mecánico, que no se ha modificado desde cuando despuntaron las primeras escuelas en el siglo XIX, pese a las retos y transformaciones que le ha correspondido afrontar a los sistemas educativos de América Latina. Aunado al hecho de que comparativamente los estudiantes latinoamericanos tienen menos horas de trabajo académico en comparación con los de Europa, Estados Unidos y el sudeste asiático.

La tendencia mundial desde la década de 1980, es a aumentar la jornada escolar y el calendario académico. Numerosos estudios e informes han coincidido 
en la relación positiva que se da entre un mayor tiempo de escolaridad y los resultados académicos de los educandos; es decir, entre más tiempo en la jornada escolar mejores son los resultados académicos (Martinic, 2015, p. 83-85) frente a experiencias como las dobles jornadas; pero para el caso colombiano no se han reportado relaciones.

Se puede tener o disponer de varias interpretaciones o experiencias sobre el tiempo escolar, su organización y uso; también sobre su incidencia en los aprendizajes; de la misma manera, asumir una u otra postura a propósito de las reformas a la jornada y al calendario escolares, pero es necesario reconocer que la calidad de la educación y el nivel de logro de los educandos están también asociados a otros factores y realidades sociales y pedagógicas, tienen que ver con la calidad del uso de ese tiempo y la pertinencia de las metodologías; la calidad, la innovación y la pertinencia de los aprendizajes tienen que ver con el entorno escolar y las posibilidades familiares y culturales.

El uso y control del tiempo escolar ha sido objeto de una minuciosa regulación jurídica y de unas determinadas políticas públicas que impactan diversos aspectos o tópicos del mundo de la escuela que, en el período actual, tiene los mismos referentes ideológicos que han orientado las políticas de reforma en otros ámbitos del Estado y la economía, tal como lo argumenta Miñana Blasco (2008):

\begin{abstract}
El nuevo Estado ha construido ciudadanos iguales, instituciones educativas iguales, con horarios y unidades temporales iguales, y ha sido $-\mathrm{a}$ pesar de la Constitución de 1991 que consagraba la diversidad - indiferente a la diferencia; la única diferencia que reconoce es la frontera de la pobreza cuya definición y límites crea y maneja a su antojo con sofisticados sistemas de información (Sisbén), la frontera que le sirve para distinguir entre los que debe regular y los que debe tutelar (2008, pp. 48-49).
\end{abstract}

Un proceso de reorganización del Estado, la economía y los servicios sociales, entre ellos la educación y la jornada escolar, marcan los derroteros de las políticas públicas en Colombia y la región a partir de finales de la década de 1980; en esa medida se han efectuado ajustes a los esquemas de financiación y gestión de la educación articulados a los requerimientos de la globalización y el libre mercado.

Igualmente, se ha construido un concepto de eficacia educativa desde la sincronización temporal de la circulación de los estudiantes por el sistema. La «unidad temporal de producción» se ha homogeneizado y simplificado, al igual que la unidad temporal laboral, mientras que se intentaba flexibilizar el horario de las docentes exigiendo de ellas una disponibilidad 
total que se adaptara a las necesidades de la "producción» (caso de las coordinadoras, rectoras, orientadoras, de todas las docentes en el sector privado y de las monitoras y docentes que asumen las actividades complementarias)... El tiempo escolar no parecería estar al servicio del «aprendizaje» como señalaba la campaña del Ministerio, sino al servicio del tiempo ordenado (Miñana Blasco, 2008, p. 46).

Colombia ha experimentado, especialmente desde mediados del siglo XX, un relativo avance de los indicadores en materia educativa (presupuesto invertido, estudiantes matriculados, número de docentes al servicio de la educación oficial, número de instituciones educativas). Pero de todos modos son evidentes los problemas de acceso a la educación superior, de financiación de la educación pública en este nivel, de consolidación del predominio privado y crisis de la universidad pública con la Ley 30 de 1992 (Blanco 2009, p. 142), de pertinencia y oportunidad de los instrumentos de inspección y vigilancia hacia la universidad privada; igualmente los reparos a la política pública educativa en los niveles de preescolar, básica y media no se han dejado esperar; reparos frente a la coherencia y pertinencia de los mecanismos de financiación, normas y procedimientos relacionados con la gestión pública del servicio, el régimen laboral, la democracia escolar, las evaluaciones externas, los condicionamientos curriculares, entre otros asuntos, desde los cuales se preserva un sistema de educación pública y con ella, la garantía del derecho a la educación de los niños, niñas y jóvenes (Bocanegra, 2015 y Lenis Mejía, 2017).

La fusión de colegios que el país y la ciudad experimentaron en la década de 1990, tuvo en la formalidad del discurso oficial el propósito de asegurar continuidad a los estudiantes en los diferentes ciclos y niveles. En términos de la realidad institucional y pedagógica de las instituciones representó una imposición, un proceso mediado por la fuerza, desde el cual se intervienen y reducen las plantas de personal docente y de directivos docentes en una lógica no pedagógica sino fiscal. Un solo rector o rectora tendría la responsabilidad de administrar tres o cuatro sedes; una decisión que responde a la política de austeridad que predomina en este periodo de auge del modelo económico neoliberal. Como lo analiza Blanco Suárez para el caso de la educación superior: «la búsqueda de una reducción general de costos de la formación de los colombianos» (2009, p. 150). Hacer más con menos, como se denunció respecto a la política de jornada única, donde a pesar de los cambios en los horarios escolares, subsisten problemas administrativos, laborales, financieros, de seguridad y convivencia, de bienestar estudiantil, es decir, de condiciones para la existencia de una jornada escolar única diurna, con lo que se ponen trabas adicionales al cumplimiento de los objetivos misionales de las instituciones educativas y a los logros formativos de los educandos. Al respecto resulta válido el planteamiento de Miñana Blasco: 
Asociados a los cambios temporales se ha dado también una reorganización de la gestión concentrando la administración de varias escuelas cercanas en un colegio de secundaria; igualmente se han introducido recientemente sistemas de rotación de los espacios, sofisticación espaciotemporal para mejorar la eficiencia en los usos de los espacios y poder aumentar la cobertura (Miñana Blasco, 2008, p. 44).

\subsection{La jornada única como política pública en Colombia}

Las diferentes acciones de Estado, para atender necesidades colectivas, en este caso de permanencia de los educandos en el colegio y la calidad de la educación, tienen que ser estudiadas desde unos referentes teóricos conceptuales y metodológicos pertinentes. Desde esta consideración se asumirá, en este ejercicio investigativo, la teoría del análisis de políticas públicas como un referente teórico, conceptual y metodológico para el abordaje de las acciones que viene desplegando el Estado en materia de jornada única escolar en Colombia, con todo lo que estructuralmente ellas implican en ordenamiento jurídico, administrativo y pedagógico del sector y de los establecimientos educativos. «El análisis de las políticas públicas se efectúa desde una metodología de investigación social que aborda la actividad concreta de las autoridades públicas, "al qué y al cómo hacer del Estado"» (Rohh Deubel, 2004, p. 15).

Las políticas públicas en un plano formal se formulan desde unas necesidades o problemas sociales que requieren ser atendidos por las autoridades competentes; «aquella dimensión de la actividad humana que se cree que requiere la regulación o intervención gubernamental o social, o por lo menos la adopción de medidas comunes» (Parsons, 2009). En el caso concreto de atender los problemas de calidad educativa y permanencia de los estudiantes asociados a las dobles jornadas escolares existentes en el país y al propósito político de avanzar por la senda de la jornada única escolar, el gobierno nacional propuso una hoja de ruta que lo llevó inicialmente a expedir una normatividad que ha sido objeto de reajustes y que ha producido pronunciamientos y reacciones adversas por parte de los docentes organizados gremialmente.

La jornada escolar, y en este caso concreto la jornada única, se convierte en uno de los componentes de la política pública educativa, que en el plano formal y práctico se debe articular a otras acciones del Estado; no es concebible la extensión del horario y el calendario escolar sin la materialización del plan de alimentación escolar, sin los ajustes curriculares del caso, sin la dotación de la infraestructura y sin la definición de las estrategias para atender la conflictividad escolar suscitada por una mayor permanencia de estudiantes dentro de los recintos escolares. Otros ámbitos de la gestión administrativa y 
de la política educativa tienen relación directa con el tema de la jornada única: la financiación, la distribución de recursos y competencias entre las entidades territoriales, los mecanismos y criterios para administrar el personal docente vinculado al sector estatal, la evaluación de los educandos y del servicio, las estrategias de cobertura, accesibilidad y pertinencia. De todos modos, como se planteó anteriormente, la política pública de jornada única no admite opciones; es de estricto acatamiento por instituciones educativas y autoridades de las entidades territoriales certificadas en educación.

\subsection{El marco jurídico: de la doble a la jornada única escolar}

La Constitución Política de 1991 reconoce a la educación como un derecho de la persona y un servicio público que tiene una función social (Colombia. Constitución política, artículo 67); este derecho ha tenido una abundante reglamentación legal y un desarrollo jurisprudencial sobre los más variados tópicos. Asuntos como la jornada única han sido objeto de reglamentación de acuerdo con las facultades que otorga la Constitución Política al ejecutivo y en el marco de los objetivos de una política pública educativa que intenta romper con una larga tradición y cultura educativa de dobles y triples jornadas que ha predominado durante más de cincuenta años en el país.

Desde finales de la década de 1960, la educación pública colombiana y una proporción de la educación privada afrontó una realidad en materia de disposición del tiempo escolar: las dobles y triples jornadas (mañana, tarde y noche) que se tuvieron que establecer, inicialmente de manera transitoria, ante una demanda apremiante de cupos escolares. Por medio del Decreto 0155 de 1967 se autorizó el funcionamiento de planteles de doble jornada y se establecieron tablas de precios (derechos de matrícula y pensión) que las familias deberían sufragar por el ingreso de niños y jóvenes a los colegios oficiales en el nivel medio (Colombia. Presidencia de la República, Decreto 0155 de 1967, art. 1.²).

Desde unas precisas consideraciones el presidente de la República, en uso de sus facultades legales, le dio existencia a las dobles jornadas escolares diarias en Colombia, modificando la jornada única que tenían la mayoría de los estudiantes del sector oficial. La justificación de la decisión se encuentra sintetizada en la parte considerativa de la mencionada norma que, entre otras cosas, señalaba la necesidad de «satisfacer la creciente demanda de cupos en los planteles de enseñanza primaria y media en todo el territorio nacional y se hace indispensable adoptar un plan de emergencia» (Colombia. Presidencia de la República, Decreto 0155 de 1967).

Adicionalmente, de estos considerandos se infieren algunas cosas: se presentó como una medida de emergencia, transitoria en los niveles de primaria y me- 
dia (bachillerato); la política contó con la aquiescencia de otros actores del proceso educativo: el magisterio oficial, los padres de familia, la educación privada y los directivos docentes a ella vinculados, es decir, contó con un ambiente de relativo consenso.

Complementariamente, el Decreto 0155 introdujo ajustes en la asignación académica de los docentes y directivos docentes respecto a lo que inicialmente se tenía establecido por mandato en el Decreto 30 de 1948 (enero 12) reglamentario del artículo $7 .^{\circ}$ de la Ley 64 de 1947, que modificó el mismo artículo de la Ley 43 de 1945 (diciembre 17) con la que se creó el escalafón nacional de enseñanza secundaria. Con respecto a estas disposiciones, la doble jornada implicó una mayor carga de horas clase para todos los docentes e incluso directivos docentes y la necesaria modificación del referido artículo 33 del Decreto 30 de 1948 (Colombia. Presidencia de la República. Decreto 0155 de 1967, art. 2. ${ }^{\circ}$ ).

Durante décadas la organización del sistema educativo público se acomodó a los requerimientos y necesidades en materia de construcciones escolares, dotación y provisión de las plantas de personal docente desde la realidad de las dobles y triples jornadas que funcionaban en un mismo edificio, incluso con rectores, coordinadores, orientadores y profesores distintos, que actuaban cada cual por su lado, pero afrontando las dificultades, pleitos y deterioro acelerado de unas mismas plantas físicas y los recursos audiovisuales y didácticos que cotidianamente compartían.

Hasta la Ley 115 de 1994 (capítulo IV) y el Decreto Reglamentario 1860 de 1994, constituidos en principal referente jurídico de la política pública educativa en Colombia, se estableció una regulación sobre la materia con alguna visión de futuro que permitiera desmontar el señalado experimento. Estas normas, promulgadas en el marco de una amplia discusión nacional, permitieron redefinir la organización institucional del sector en los niveles de preescolar, básica (ciclos primario y secundario) y educación media. Las nuevas formas de concebir la democracia, el gobierno escolar y la autonomía curricular, que fueron piezas claves de este reordenamiento, permitieron explorar nuevas posibilidades pedagógicas para la diversidad de instituciones, públicas y privadas, que hacen parte del sistema educativo colombiano.

El tiempo escolar se convirtió en un asunto de especial atención por parte de las autoridades públicas y una de las prioridades dentro de las políticas educativas nacionales y distritales a partir de la segunda mitad de la década de 1990, junto a otros tópicos de una relevancia indiscutible: el problema de la financiación del servicio, las competencias de las entidades territoriales, el régimen laboral y prestacional de los docentes y directivos docentes, la calidad, la cobertura, la pertinencia, entre otras cosas. Conveniente reconocer que: 
...los gobiernos colombianos en estos últimos años han centrado el concepto de calidad para el sector público en educación en dos aspectos: la evaluación censal de competencias a todos los niños del país en los grados 3. ${ }^{\circ},{ }^{\circ}{ }^{\circ}$ y $9 .^{\circ}$ (especialmente en matemáticas, lenguaje y valores ciudadanos), y el incremento del «tiempo para el aprendizaje» y su uso «eficiente», es decir, sin aumentar la inversión (Miñana Blasco, 2008, p. 42).

En materia de jornada escolar el ordenamiento jurídico de 1994 (Ley 115 de 1994, artículo 85 y el Decreto 1860 de 1994, artículo 57) planteó un propósito, el establecimiento progresivo de la jornada única diurna en el marco o de acuerdo con las necesidades en materia de oferta y demanda de cupos, es decir, en la medida que las necesidades del servicio educativo lo permitiesen. Se estableció que los colegios podrían brindar dos jornadas escolares, una diurna y otra nocturna (reservada exclusivamente para la educación de adultos), bajo el compromiso de una misma administración escolar.

Con la Ley 1753 de 2015, «por la cual se expide el Plan Nacional de Desarrollo 2014-2018 todos por un nuevo país», se reformó el artículo 85 de la Ley 115 de 1994, quedando de la siguiente manera:

Jornadas en los establecimientos educativos. El servicio público educativo se prestará en las instituciones educativas en jornada única, la cual se define para todos los efectos, como la jornada única en la cual los estudiantes desarrollan actividades que forman parte del plan de estudios del establecimiento educativo y el receso durante al menos siete (7) horas al día. Tratándose de preescolar el tiempo dedicado al plan de estudios será al menos de seis (6) horas.

Las secretarías de educación implementarán los mecanismos para asegurar que los establecimientos educativos entreguen, dentro de sus informes periódicos de evaluación, la relación del total de horas efectivas desarrolladas en cada una de las áreas obligatorias y fundamentales, establecidas por la Ley General de Educación.

Excepcionalmente, cuando las limitaciones del servicio educativo impidan el desarrollo de la jornada única, podrán ofrecerse dos jornadas escolares, una diurna y otra nocturna, bajo la responsabilidad de una misma administración. La jornada escolar nocturna se destinará, preferentemente, a la educación de adultos de que trata el Título III de la presente ley.

Parágrafo. El Gobierno nacional y las entidades territoriales certificadas en educación, diseñarán planes para la implementación, de forma gradual, de la jornada única en un plazo que no supere al año 2025 en las 
zonas urbanas y el 2030 para las zonas rurales. En el proceso de diseño, las facultades de educación del país, las juntas de asociación de padres de familias y los docentes podrán ser consultados.

El interés por prolongar o extender el tiempo escolar, no solo de trabajo en el aula con estudiantes, sino en actividades docentes de planeación, organización, capacitación o retroalimentación, derivó en la expedición de varias normas tendientes a optimizar el uso y control sobre el tiempo en la escuela, las semanas anuales de clase, las semanas de trabajo institucional docente sin estudiantes, los períodos de clase, las semanas de receso estudiantil, las semanas de vacaciones de docentes, la jornada laboral docente y la jornada escolar. Entre ellas, la Resolución Ministerial 144 de 2001; La ley 715 de 2001, reglamentaria del Acto Legislativo 01 de 2001; la Ley 1753 de 2015; el Decreto Reglamentario 1850 de 2002 sobre jornada laboral y asignación académica; los decretos reglamentarios en materia de jornada única escolar expedidos a partir de 2014, los Decretos 1075 de 2015 y 501 de 2016, Decreto 2105 del 14 de diciembre de 2017, así como los actos administrativos en la misma materia expedidos por la administración en Bogotá, entre ellos la Resolución Distrital nro. 8124 de 1998, que citamos por el valor estratégico que tiene la capital de la república en el concierto político administrativo subnacional de Colombia.

Con el Decreto 2105 de 2017, modificatorio del Decreto 1075 de 2015, Único Reglamentario del Sector Educación, se pretende darle coherencia al andamiaje institucional desde el cual se implementa, entre otras cosas, la jornada única escolar. Esta disposición la define con suma claridad, establece su duración, las condiciones para su reconocimiento, los objetivos, la asignación académica semanal de los docentes de aula en jornada única para el desarrollo de las actividades académicas, los requerimientos y acciones del componente de recurso humano para la implementación de la jornada única. De otra parte, esta norma establece orientaciones respecto al concurso y tipos de cargos docentes, reubicación de cargo docente, perfil del cargo directivo docente, la terminación del nombramiento provisional y los encargos.

La política pública educativa de jornada única escolar, en general el uso y control de los tiempos en la escuela, en el contexto actual de Colombia, se ha constituido en un factor de tensiones entre los diferentes actores y autoridades educativas. Pero este asunto involucra un conjunto de situaciones e intereses de orden profesional, laboral y pedagógico al igual que enfrenta nociones y perspectivas sobre el papel de la escuela, su autonomía, los derechos laborales y el bienestar de los docentes y la política fiscal y presupuestal, considerando que el tipo o modalidad de jornada escolar que se asuma tiene unos efectos sobre la inversión pública. 


\section{LA EXPERIENCIA DE IMPLEMENTACIÓN DE LA JORNADA ÚNICA EN UNA INSTITUCIÓN EDUCATIVA DISTRITAL}

\subsection{Los aspectos metodológicos}

La investigación es de carácter sociojurídico en la medida que relaciona la acción del Estado frente a la educación en cuanto derecho fundamental; conforme a los objetivos específicos y los requerimientos de orden teórico y metodológico, en esta fase la investigación se desarrolla desde un enfoque cuantitativo. El ejercicio investigativo desarrollado requirió recolectar, seleccionar y procesar la información desde la cual se reconociera la realidad de la implementación de la jornada única en una institución educativa distrital de la Localidad de San Cristóbal (Bogotá D. C.) desde la percepción de sus estamentos básicos, aplicando una encuesta basada en los presupuestos de Connors y Morris (2014).

La encuesta presentó dos categorías; la primera evaluó aspectos curriculares y la segunda, lo convivencial. La encuesta fue validada por medio del juicio de tres expertos; estos identificaron aspectos por mejorar, los cuales se ajustaron para la aplicación en la institución educativa. El cuestionario contiene 45 preguntas; cada uno de los ítems podría ser valorado en una escala de 1 a 5, que identificaba valoraciones específicas como: deficiente (1), regular (2), aceptable (3), bueno (4), excelente (5).

A continuación se presentan las preguntas relacionadas con los aspectos curriculares, que se encuentran divididos en cuatro subcategorías: 1) Organización curricular, 2) Infraestructura e insumos, 3) Procesos docentes y 4) Tiempo y parámetros. Se anexa a este artículo el instrumento aplicado. Tabla 1.

La segunda categoría que evaluó aspectos convivenciales presenta también cuatro subcategorías: 1) Gobierno escolar, participación y toma de decisiones, 2) Normatividad y Ruta de Atención Integral a la Convivencia Escolar, 3) Seguridad y convivencia escolar y 4) Bienestar estudiantil. La tabla 2 presenta las preguntas de esta categoría. Tabla 2.

La encuesta permitió recoger información sobre la implementación de la jornada única en un colegio oficial de Bogotá, por medio de la apreciación de los integrantes de sus estamentos básicos: estudiantes (21); padres o acudientes (8); docentes (8); orientadores escolares (2); directivos (3).

\subsection{Resultados y análisis}

La institución objeto del estudio está ubicada en la Localidad Cuarta de San Cristóbal, en la Capital de la República. Se escogió esta IED por la trayectoria 
Tabla 1. Subcategorías: aspectos curriculares

\section{Organización curricular}

101. Transformaciones pedagógicas, nuevas áreas o proyectos pedagógicos.

102. Plan de estudios.

103. Prevención del fracaso escolar y la reprobación.

104. Orientación vocacional y profesional.

105. Proyecto de dirección de curso.

106. Diálogo con los padres y oportunidad en la entrega de informes académicos.

107. Funcionamiento de Consejo Académico y Comités de evaluación y promoción.

\section{Infraestructura e insumos}

108. Disposición del número de aulas necesarias.

109. Disposición y uso del espacio al aire libre o deportivos: número y tipo de escenarios para la práctica deportiva.

110. Disposición y uso de recursos tecnológicos, informáticos, audiovisuales.

111. Disposición de materiales o insumos para actividades académicas: marcadores, papelería, balones.

112. Disposición de aulas especializadas: laboratorios, informática, bilingüismo, diseño.

113. Disposición de aulas especializadas: gimnasio, de danzas, de música, de artes plásticas.

\section{Procesos docentes}

114. Utilidad de la evaluación docente.

115. Planes de mejoramiento docente.

116. Seguimiento y control académico y asistencia.

117. Programas de actualización y formación docente.

118. Participación docente en la organización académica

\section{Tiempo y parámetros}

119. Uso del tiempo adicional y cumplimiento de horario según criterios.

120. Número de estudiantes por aula.

121. Número de docentes según necesidades institucionales.

122. Control de asistencia y permanencia de docentes.

123. Control de asistencia de estudiantes a jornada y clases. 
Tabla 2. Subcategorías: aspectos convivenciales

\section{Gobierno escolar, participación y toma de decisiones}

124. Funcionamiento del gobierno escolar y proceso de toma de decisiones.

125. Funcionamiento del Comité Institucional de Convivencia.

126. Proyecto de convivencia y formación ciudadana.

127. Participación de los padres en procesos de acompañamiento y orientación convivencial.

128. Convenios interinstitucionales para el acompañamiento, asesoría, consultoría o apoyo convivencial.

129. Procesos de mediación y conciliación.

\section{Normatividad y Ruta de atención Integral a la Convivencia Escolar}

130. Manual de Convivencia y Ruta de Atención Integral a la Convivencia Escolar conforme a la Ley 1620 de 2013 y el Decreto 1965 de 2013.

131. Seguimiento al debido proceso y conducto regular.

132. Atención a la violencia escolar, violencia en la escuela y violencia contra la escuela.

133. Autoevaluación convivencial de los escolares.

134. Periodicidad de reuniones de docentes o equipos docentes para análisis de problemática convivencial y retroalimentación de procesos convivenciales.

135. Seguimiento convivencial con acudientes.

136. Promoción de los derechos humanos.

\section{Seguridad y convivencia escolar}

137. Vigilancia y seguridad interna.

138. Seguridad de los entornos escolares.

139. Clima laboral.

140. Apoyo de otras autoridades competentes: ICBF, Policía, Comisaría de Familia, Hospital.

141. Asesoramiento y seguimiento del nivel central.

\section{Bienestar estudiantil}

142. Plan de Alimentación escolar

143. Prevención, atención y seguimiento de consumo de SPA.

144. Prevención del embarazo adolescente.

145. Servicio de orientación y consejería escolar. 
académica y administrativa que trae; porque tiene todos los niveles educativos, incluso de educación tecnológica en convenio con el SENA; porque tuvo una implementación de jornada única en un lapso relativamente corto.

El colegio inició labores en 1980 integrado al programa denominado Complejo de Educación Media Diversificada de la Zona Sur Oriente de Bogotá (CEMDIZOB). Tiene 2000 estudiantes, funciona en tres sedes, con 110 funcionarios docentes, de los cuales 7 son directivos y 4 son orientadoras escolares; desarrolla su actividad formativa en los niveles de educación preescolar, básica y media técnica articulada con el Servicio Nacional de Aprendizaje (SENA) y permite el funcionamiento del nivel tecnológico en tres especialidades en convenio con esta misma entidad.

Desde el año 2016 se incorporó a la organización institucional la jornada única, una vez se surtieron las discusiones y aprobación por parte de los órganos del gobierno escolar y posteriormente la anuencia de la autoridad educativa distrital competente. El proceso avanzó desde un relativo consenso respecto a las implicaciones que en materia de horarios, jornada laboral y reorganización curricular podría traer esta decisión, pero igualmente considerando las dificultades que en materia de disminución de plazas docentes estaba generando la baja de matrícula en las dos jornadas, pero especialmente en la jornada de la tarde, según lo dejan ver testimonios de seis profesores de las áreas de sociales, humanidades, matemáticas y tecnología, y dos coordinadores (comunicación personal, junio de 2018).

La institución contaba con la infraestructura en bachillerato para iniciar con la jornada única. Entonces en los niveles de básica secundaria y media se inicia la experiencia en el año 2016; sucede lo mismo en preescolar y los grados primero y segundo. Por su parte en el nivel de básica primaria, en los grados tercero, cuarto y quinto, se operó un período de transición hasta el año 2018, cuando ingresan definitivamente en jornada única, situación facilitada por el número de estudiantes matriculados y los ajustes institucionales realizados.

El colegio cuenta, en su sede A (donde funciona bachillerato), con cocina móvil, espacios acondicionados como restaurante escolar, teatro para 300 personas, dos salas de audiovisuales, laboratorios de ciencias dotados, tres canchas deportivas múltiples, y en general unas plantas físicas suficientes respecto al número de estudiantes y necesidades educativas. En las otras dos sedes (B y C) se cumple con los mínimos estándares para el funcionamiento adecuado del servicio. El proceso de la jornada única ha marchado conforme a la planeación, sin mayores contratiempos, lo que no oculta las inconformidades que algunos docentes expresan frente a los ajustes en la jornada laboral, la necesidad de flexibilizarla para poder organizar los horarios de clase, y respecto a una 
supuesta sobrecarga laboral docente generada en el colegio desde la adopción de la jornada única.

En el marco de esta iniciativa investigativa evaluativa, se pudo indagar entre los miembros de la comunidad educativa del referido colegio su percepción sobre la incidencia curricular y convivencial de la jornada única en ese particular contexto socioeducativo, $f$ utilizando la técnica de encuesta, en una muestra representativa de estudiantes (21), padres o acudientes (8), docentes (8), orientadores escolares (2) y directivos (3). Una vez realizada la respectiva tabulación y visualizados los resultados, en porcentajes, se procedió a leerlos y establecer las tendencias o propensiones en cada uno de los ítems del cuestionario aplicado.

De los resultados de las encuestas aplicadas podemos inferir lo siguiente en la parte curricular: en general los estamentos hacen una buena ponderación de los desarrollos curriculares que la institución ha tenido con la implementación de la jornada única. El subtema de organización curricular se mueve predominantemente en una ponderación de aceptable a excelente. En cuanto a los ítems de las transformaciones pedagógicas (101), predomina en estudiantes, directivos docentes y padres de familia una ponderación entre 4 y 5 , mientras que el cuerpo de orientadores le da una ponderación de deficiente (1), lo cual indica un cuestionamiento sobre los recursos y medios asignados.

En lo correspondiente al plan de estudios (102) se otorga una valoración mayoritaria de 4 por parte de todos los estamentos; nuevamente exceptuando a los orientadores, que dan una calificación baja. En prevención del fracaso escolar y reprobación (103) se destaca la ponderación de aceptable que mayoritariamente la asignan docentes (supera el 80\%) y directivos (supera el $65 \%$ ), lo que implicaría una propuesta institucional que permitiera bajar los niveles de fracaso escolar.

El subtema de infraestructura e insumos (108 a 113) recibe predominantemente una ponderación que oscila entre aceptable y excelente. El ítem de disposición del número de aulas necesarias (108) recibe una ponderación que se ubica entre bueno y excelente, destacándose la de padres o acudientes con una positiva percepción sobre el punto. Pero el ítem correspondiente a disposición y uso del espacio al aire libre o deportivo (109) tiene una ponderación que predomina entre lo deficiente y lo aceptable, especialmente entre docentes, estudiantes y orientadores, debido a que la institución carece de zonas verdes aptas para la recreación pasiva o el descanso: apenas dispone de una zona verde escarpada y con cierto deterioro. En materia de disposición y uso de recursos tecnológicos, informáticos y audiovisuales (110), directivos y orientadores lo ponderan como aceptable; sobresale la ponderación baja que le asignan a este asunto los orientadores; pero los estudiantes le dan una valoración que se mueve entre bueno y excelente. Gráfico 1. 


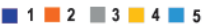

ORIENTADORES

$\doteq$ DOCENTES

DIRECTIVOS

ACUDIENTE

ORIENTADORES

ESTUDIANTES

ฐ DOCENTES DIRECTIVOS

ACUDIENTE

ORIENTADORES

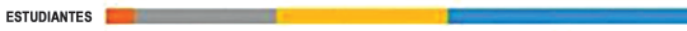

$\cong$ DOCENTES Da

DIRECTIVOS

ACUDIENTE

ORIENTADORES

ESTUDIANTES

$\stackrel{ \pm}{\square}$ DOCENTES

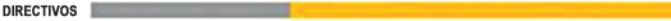

ACUDIENTE

ORIENTADORES

ESTUDIANTES

$\stackrel{0}{\circ}$ DOCENTES

DIRECTIVOS

ACUDIENTE

ORIENTADORES

ESTUDIANTES

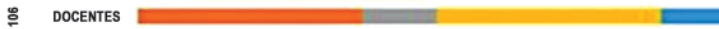

DIRECTIVOS

ACUDIENTE

ORIENTADORES

ESTUDIANTES

D. DOCENTES DI

DIRECTIVOS

ACUDIENTE

ORIENTADORES

ESTUDIANTES

DOCENTES

DIRECTIVOS

ACUDIENTE

ORIENTADORES

ESTUDIANTES De

\$ DOCENTES DIRECTIVOS

ACUDIENTE Dan

ORIENTADORES

ESTUDIANTES Dan

DOCENTES D

DIRECTIVOS

ACUDIENTE

ORIENTADORES

ESTUDIANTES

$\equiv \quad$ DOCENTES DIRECTIVOS

ACUDIENTE

ORIENTADORES

ESTUDIANTES EIST

$\cong$ DOCENTES DOS

DIRECTIVOS Eim

ACUDIENTE

ORIENTADORES

Estudiantes

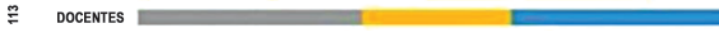

DIRECTIVOS

ACUDIENTE

Gráfico 1. Organización curricular, infraestructura e insumos 
En el subtema de procesos docentes se destaca la valoración que se hace en algunos ítems; por ejemplo, sobre utilidad de la evaluación docente (114) se muestra una percepción negativa entre orientadores y aceptable entre directivos. En los planes de mejoramiento docente predomina una valoración de bueno entre los docentes, estudiantes, padres y directivos, pero una percepción negativa entre los orientadores escolares. Percepción negativa que se da igualmente respecto a otros ítems evaluados con la encuesta, entre ellos, seguimiento y control académico y asistencia (115), programas de actualización docente en la organización académica (117) y participación docente en la organización académica (118) que en alguna medida contrasta con lo que registran otros estamentos. En el subtema de tiempo y parámetros (119 a 123), asunto sensible para los intereses de maestros y directivos, se nota una percepción que oscila entre lo aceptable y lo bueno. Gráfico 2.

Los resultados de cada subcategoría perteneciente a los aspectos convivenciales se presentan en los gráficos 3 y 4 .

En el aspecto convivencial, de los resultados de la encuesta aplicada se puede inferir lo siguiente: los estamentos hacen una ponderación en general aceptable del subtema Gobierno escolar, participación y toma de decisiones (124 a 129). En el subtema normatividad y Ruta de atención Integral a la Convivencia Escolar (130 a 136) se destacan los ítems Manual de Convivencia y Ruta de Atención Integral a la Convivencia (130) y Seguimiento al debido proceso y conducto regular (131), con una ponderación entre bueno y excelente. El ítem puede estar ponderado de manera positiva en la medida en que la institución desarrolla su Proyecto de Convivencia y Ciudadanía que contempla un conjunto de estrategias y acciones en esta materia, incluso antes de la implantación de la jornada única: participación institucional en el Proyecto Hermes con la Cámara de Comercio de Bogotá en la formación de mediadores y gestores convivenciales entre los estudiantes en un ejercicio desde hace cuatro años; la Semana de la Sana Convivencia, constituida en un espacio de reflexión y formación en principios y valores; la Semana de los Afectos y el Carnaval de los Afectos que desde la lúdica y la expresión artística procura enaltecer los comportamientos positivos, el respeto al otro y la creatividad; la Pedagogía del Debido Proceso, propuesta de formación y reflexión frente a la aplicación oportuna y correcta del manual de convivencia, los principios, protocolos y procedimientos en materia convivencial, conforme a la Ley 1098 de 2006 (Código de Infancia y Adolescencia) y a la Ley 1620 y el Decreto Regalmetario1965 del 2013 que crearon el Sistema Nacional de Convivencia Escolar.

Un ítem de significado en el contexto escolar como el de atención a la violencia escolar, violencia en la escuela y violencia contra la escuela (132) recibe una 


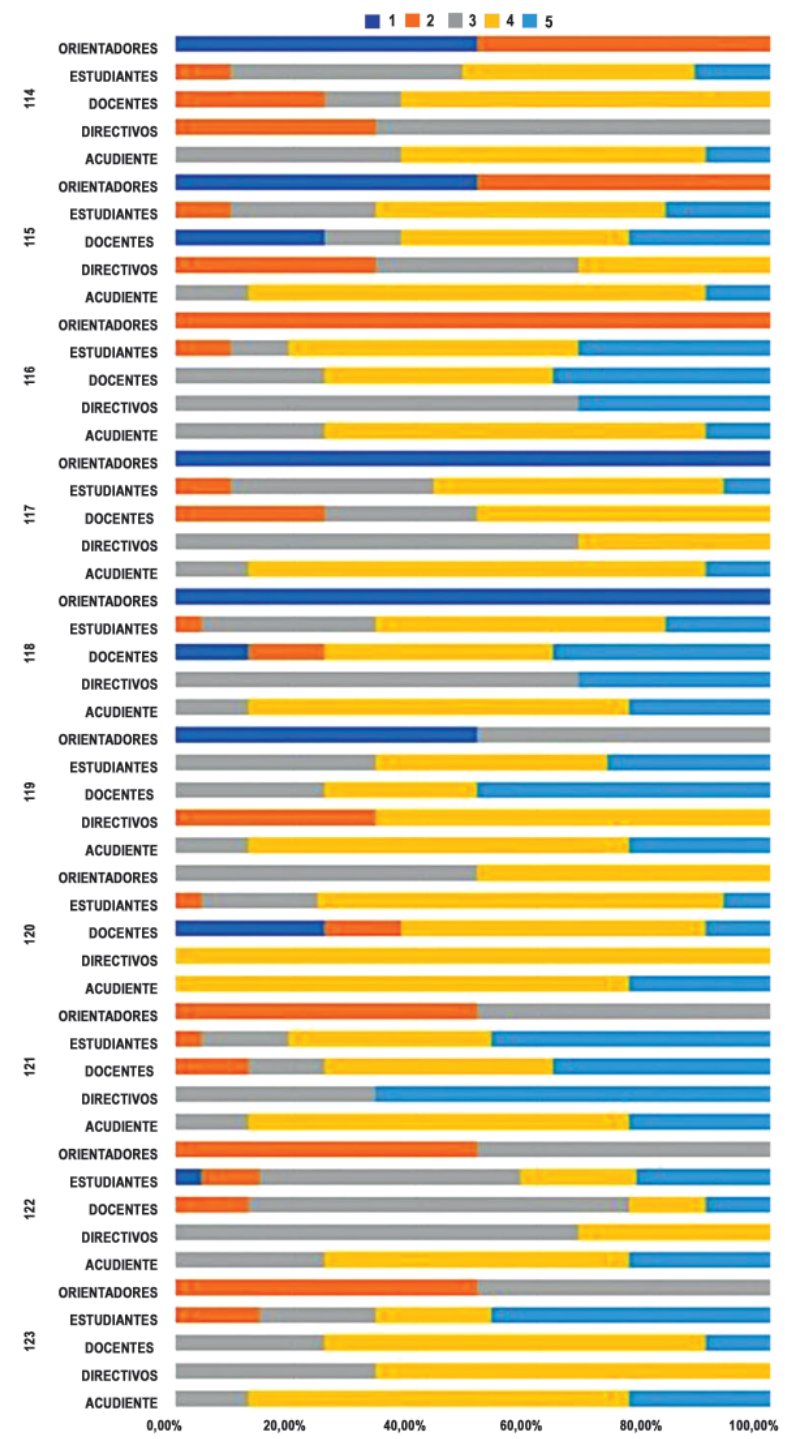

Gráfico 2. Procesos docentes, tiempo y parámetros.

calificación positiva entre todos los miembros de la comunidad educativa: la tendencia es entre aceptable y excelente. En el ítem periodicidad de reuniones de docentes o equipos de docentes para análisis de problemática convivencial y retroalimentación de procesos convivenciales (134) se evidencia una percepción negativa entre docentes (un 40\% califica como deficiente y regular); en un $100 \%$ la calificación de orientadores es deficiente. Por su parte, Seguimiento 


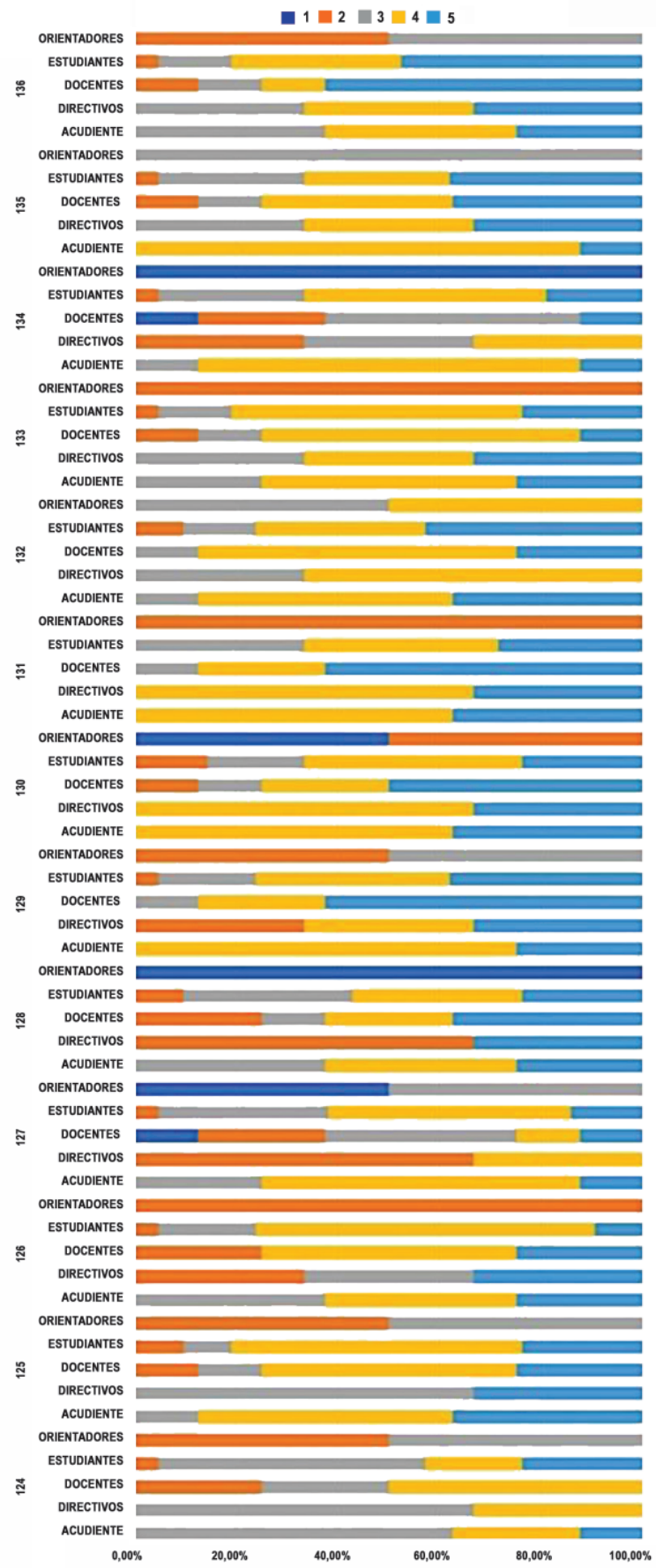

Gráfico 3. Gobierno escolar, participación, toma de decisiones, normas y Ruta de Atención a la Convivencia Escolar 


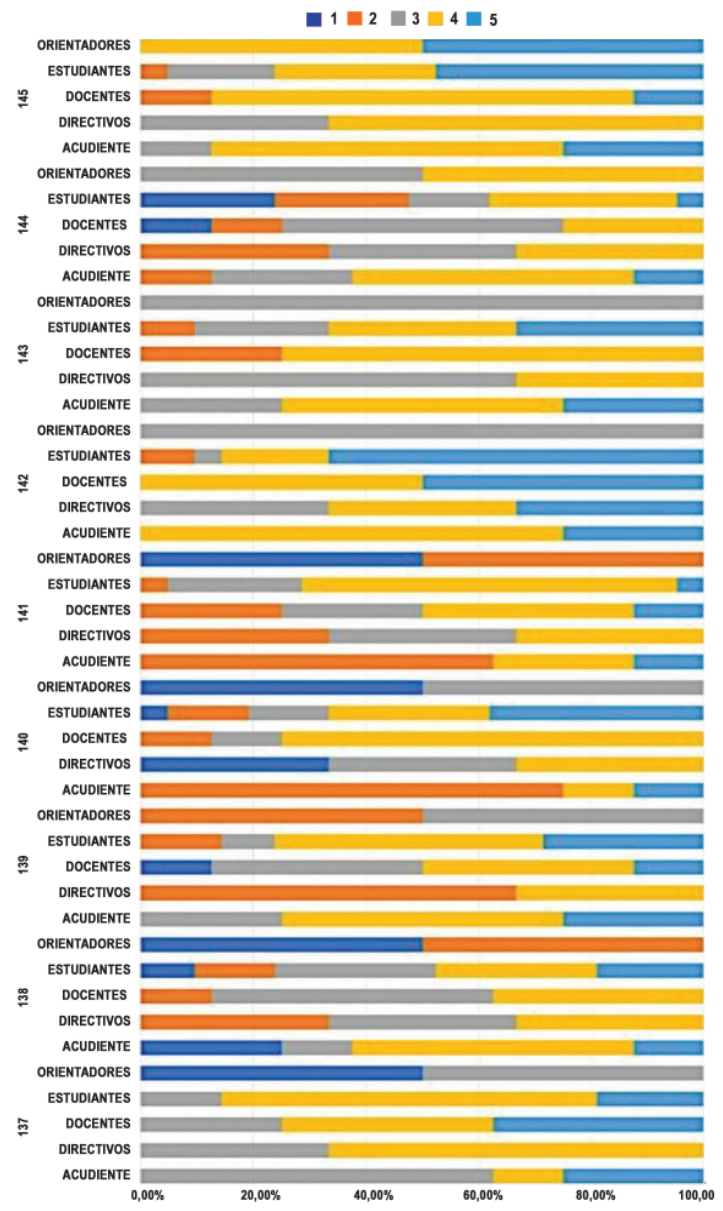

Gráfico 4. Seguridad, convivencia escolar y bienestar.

convivencial con acudientes (135), se movió predominantemente entre aceptable y excelente; igual, Promoción de los derechos humanos (136).

En el subtema de seguridad y convivencia escolar (137 a 141), lo correspondiente a la vigilancia y seguridad interna (138), la valoración que predomina entre aceptable y bueno, con excepción del grupo de orientadores que la valora como deficiente por el 50\% de encuestados. En el ítem seguridad de los entornos escolares (138) se presenta una tendencia de mayor dispersión en las percepciones: los orientadores la valoran como deficiente; entre los docentes y acudientes predomina una valoración de más del $40 \%$ entre deficiente y regular. Lo anterior debido a las apreciaciones de inseguridad que se tienen respecto a la zona donde está ubicado el colegio. 
En clima laboral (139) igual evidencia valoraciones parecidas que van desde lo regular hasta bueno de manera predominante. En cuanto al ítem de apoyo de otras autoridades competentes, como ICBF, Policía, Comisaría de familia y Hospital (140), los acudientes tienen una percepción relativamente negativa, pues $75 \%$ lo valoran de manera regular; los orientadores lo califican como deficiente en un $50 \%$. Son evidentes las limitaciones en la capacidad operativa de estas instituciones en los entornos escolares.

En materia de asesoramiento y seguimiento del nivel central (141), los resultados evidencian una gran dispersión en las respectivas valoraciones: mientras que los orientadores distribuyen sus preferencias entre deficiente y regular, los acudientes se expresan mayoritariamente con una valoración de regular y los estudiantes en más de un $65 \%$ con una valoración de bueno.

En el subtema bienestar estudiantil (142 A 145), específicamente en el plan de alimentación escolar (142), se tiene una percepción que mayoritariamente se mueve entre bueno y excelente. Mientras que prevención, atención y seguimiento de consumo SPA (143) muestra unos resultados con un mayor grado de dispersión en las respuestas: el $67 \%$ de los directivos la califica como regular, el $100 \%$ de los orientadores hace la misma valoración, el 50\% de los acudientes la valora como buena y esa misma valoración la da más del $60 \%$ de los docentes. Igual tendencia presenta la prevención del embarazo en adolescentes (144), mientras que el servicio de orientación y consejería escolar (145) está valorado entre bueno y excelente por la mayoría de los encuestados. Ahora bien, se puede interpretar esta información desde una consideración: los problemas de porte, consumo y distribución de SPA superan la capacidad operativa del cuerpo de orientadores escolares, a pesar de que desarrollan un trabajo que se visibiliza en otras acciones.

\section{CONCLUSIONES}

En esta sección se presentan las conclusiones del estudio en la perspectiva de darles respuesta a los interrogantes desde los cuales se le dio forma al problema de investigación. Inicialmente plantearemos lo correspondiente a los elementos históricos y los lineamientos conceptuales, políticos y jurídicos desde los cuales se ejecuta la política de jornada única. Posteriormente sintetizaremos los hallazgos a propósito de su implementación en la institución educativa distrital objeto de este ejercicio investigativo.

La jornada única presentada como una propuesta de orden pedagógico constituye una política educativa inmersa en una estrategia general de uso y control del tiempo escolar en el marco de las políticas de ajuste estructural y fiscal que 
se desarrolla en Colombia en el marco de los requerimientos de orden económico y político que se imponen con los procesos de globalización y transnacionalización de la educación, la cultura y las políticas públicas. Esta situación ha implicado dificultades en los procesos de concertación con las comunidades educativas, austeridad en la apropiación de los recursos financieros para suplir las necesidades materiales que viabilicen su adopción en condiciones aceptables, especialmente para el cuerpo profesoral e improvisación que ha llevado a reversar o revisar experiencias.

El uso del tiempo en la escuela, especialmente el referido a la jornada escolar, en cuanto condición o elemento del currículo, ha sido objeto de análisis prácticos y ejercicios de teorización y conceptualización dada la relativa relevancia que este asunto tiene en el concierto de necesidades de la escuela, de la formación de los educandos y los controles que ejecutan las autoridades públicas sobre el trabajo docente, la permanencia escolar y el uso eficiente de los recursos.

Desde la expedición de la Ley 115 de 1994 y el Decreto Reglamentario 1860 de ese mismo año, se comienza a construir un corpus jurídico regulatorio de la jornada única escolar, que ha sufrido ajustes en la medida que las circunstancias y los intereses políticos, la movilización de los sindicatos docentes y los requerimientos institucionales lo han exigido: desde el Decreto 0155 de 1967; pasando por la fórmula transitoria que estableció la Ley 115 de 1994 al respecto; la Ley 1753 de 2015, «por la cual se expide el Plan Nacional de Desarrollo 2014-2018 todos por un nuevo país», que reformó el artículo 85 de la Ley 115 de 1994; la compilación lograda con el Decreto 1075 de 2015, Reglamentario Único del sector educativo; los avances del Decreto 501 de 2016 y la consolidación normativa que se logró con el Decreto 2105 del 14 de diciembre de 2017, así como numerosos actos administrativos expedidos por el gobierno nacional y las entidades territoriales certificadas en educación. Es decir, se cuenta con una normatividad controvertida en sus fundamentos y alcances, contradictoria en algunos de sus apartes, pero desde la cual las autoridades públicas competentes y las instituciones educativas han soportado las respectivas decisiones y avances en materia de jornada única escolar diurna.

Se debe reconocer que el Gobierno Nacional procedió a reformar al Decreto 501 de 2016, que inicialmente regulaba la jornada única, expidiendo un nuevo decreto reglamentario (el 2105, del 14 de diciembre de 2017), como respuesta a los acuerdos alcanzados con la Federación Colombiana de Trabajadores y Trabajadoras de la Educación (Fecode) en el proceso de negociación colectiva llevado a cabo en el año 2017; de todos modos esta organización sindical mantiene una postura adversa a las disposiciones oficiales en la materia, reconoce que mucho de los puntos que desarrolla esta norma fueron acordados con la 
Federación, pero que de todos modos el Gobierno Nacional procedió de manera inconsulta a expedirlo sin mediar acuerdo sobre la parte sustancial, en particular en lo correspondiente a la jornada única (Restrepo, 2018).

La jornada escolar ha estado sometida a requerimientos de orden presupuestal, fiscal y político que han condicionado medidas o ajustes, unas veces disminuyendo el número de horas presenciales de los estudiantes, como ocurrió a finales de la década de 1960, y otras, aumentando la presencialidad de los educandos en el marco de unas condiciones precarias, especialmente en el ámbito de infraestructura y bienestar escolar, pero en todos los casos afectando la jornada laboral docente, la organización y las posibilidades de la educación pública. En efecto, a esta le correspondió afrontar durante 50 años dificultades en materia de construcciones escolares, dotación y provisión de las plantas de personal docente desde la realidad de las dobles y triples jornadas que funcionaban en un mismo edificio, con diferentes cuerpos profesorales, directivos y orientadores escolares, que operaban independientemente, pero enfrentando las dificultades, pleitos y deterioro acelerado de unas mismas plantas físicas y recursos audiovisuales y didácticos que tenían la obligación de compartir.

La política pública de jornada única afronta problemas de diversa naturaleza: presupuestales, laborales, de infraestructura y de contratación pública. En este último aspecto, se han presentado notorias irregularidades en un asunto clave en la ejecución de esta política: el Plan de Alimentación Escolar (PAE), que ha sido afectado por numerosos actos de corrupción, mala calidad e incumplimiento de los operadores con los términos de referencia y las condiciones contractuales; situación que naturalmente ha afectado a los estudiantes en general, pero especialmente a los que han entrado en jornada única.

La jornada única escolar ha requerido un reordenamiento institucional del sector y de las instituciones educativas no solo respecto a la ampliación, uso y control del tiempo escolar, sino en materia de manejo de los espacios y recursos, organización curricular, administración del personal docente y asignación de nuevas funciones que permita afrontar las nuevas realidades y exigencias que se derivan de su adopción institucional y los retos que ella implica en materia de bienestar estudiantil, seguridad y convivencia escolar, atención y compromiso de los padres madres y acudientes, pero fundamentalmente en la generación de procesos de innovación curricular y mejoramiento de la calidad docente y de los desempeños de los educandos.

La jornada única tendrá mayores posibilidades en términos de efectividad como política pública y posibilidad curricular en el marco de un real y efectivo ejercicio del gobierno y la democracia escolar, según lo establece la Ley 115 de 
1994 y desde la materialización de condiciones óptimas en infraestructura, gestión, financiación, currículo y bienestar estudiantil y la existencia de amplios consensos entre los actores del proceso educativo, especialmente con los docentes.

La política pública educativa de jornada única escolar, y en general el uso y control de tiempos en la escuela, en el contexto actual de Colombia, se ha constituido en un factor de tensiones entre los diferentes actores y autoridades educativas. Pero este asunto involucra un conjunto de situaciones e intereses de orden profesional, laboral y pedagógico, al igual que enfrenta nociones y perspectivas sobre el papel de la escuela, su autonomía, los derechos laborales y el bienestar de los docentes y los estudiantes, y la política fiscal y presupuestal.

Se ha evidenciado un proceso de resistencia de los principales actores del proceso educativo colombiano: los maestros, respecto a la hipotética o real incidencia pedagógica y laboral de la referida política pública sectorial. Los docentes y las organizaciones sindicales que los representan no se oponen a ultranza a la política de jornada única, pero exigen un proceso de concertación para su continuidad, la garantía de que las instituciones evalúen y propongan desde sus propias necesidades y expectativas, que cuenten con todas las condiciones materiales, financieras, de bienestar escolar, académicas y de ejercicio de la democracia y el gobierno escolar.

En 11 puntos la Asociación Distrital de Trabajadores y Trabajadoras de la Educación (ADE), principal filial de Fecode, expone los criterios que le dan contenido a la consigna de jornada única sí, pero no así, y que a su juicio deben ser considerados en la reformulación de la respectiva política pública: 1) Elaboración y/o ajuste del currículo en el marco del PEI, la autonomía, la democracia y el gobierno escolar, cuyo principal propósito es la transformación de las prácticas pedagógicas. 2) Menor número de estudiantes por curso y/o núcleo familiar atendido. 3) Nombramiento de docentes orientadores, docentes en educación física y artística, segunda lengua, tecnología e informática en los diferentes grados según necesidades institucionales. 4) Establecimiento en la asignación académica de franjas para el trabajo pedagógico, el ejercicio de la democracia y el gobierno escolar, la reflexión pedagógica y la toma de decisiones. La jornada laboral presencial se mantendrá en 6 horas diarias. 5) Mayor número de docentes, docentes orientadores, directivos docentes, administrativos y trabajadores de servicios generales, vinculados directamente por el Estado en planta de personal en propiedad. 6) Mantener, fortalecer y garantizar la plena gratuidad de la educación en Bogotá que debe ser extendida a todo el país. 7) Fortalecer la financiación estatal y adecuada de la formación docente, el apoyo a la innovación pedagógica e investigación. 8) Aumento, adaptación y reforzamiento 
estructural de plantas físicas. 9) El mejoramiento del bienestar escolar para garantizar la permanencia en la Escuela (comedores escolares, comida caliente, refrigerios, transporte escolar, campos e implementos deportivos, laboratorios, textos y bibliotecas adecuadamente dotadas y modernizadas, entre otros). 10) Un incremento salarial digno para todos los docentes, docentes orientadores y directivos docentes. 11) No detrimento de la universalización y el derecho a la educación (ADE, 2017).

El proceso de la jornada única en la institución objeto del estudio ha marchado conforme a la planeación, sin mayores contratiempos, lo que no oculta las inconformidades que docentes expresan frente a la flexibilización de la jornada laboral y respecto a una supuesta sobrecarga laboral docente generada desde la adopción del programa. De todos modos se evidencian percepciones disímiles frente a lo que ha representado la jornada única en el colegio respecto a asuntos como la disponibilidad de espacios al aire libre y para la práctica deportiva; una percepción negativa, especialmente de docentes y orientadores frente a la seguridad de los entornos escolares, aceptable en seguridad interna y convivencia; en el subtema de tiempo y parámetros, asunto sensible para los interese de maestros y directivos, la percepción que se tiene al respecto oscila entre lo aceptable y lo bueno; en materia curricular se tiene una percepción generalizada que oscila entre bueno y aceptable.

\section{REFERENCIAS}

Álvarez Gallego, A. (2010). Formación de nación y educación. Bogotá: Siglo del Hombre (Colección Culturas Pedagógicas).

Asociación Distrital de Trabajadores y Trabajadoras de la Educación. (29 de junio de 2017). Criterios para una jornada única digna. Disponible en http://www.ade bogota.org/index.php/multimedia/jornadas-de-sensibilizacion/7507-11-criterios-para-una-jornada-unica-digna

Ávila Penagos, R. (2002). Las relaciones entre la educación y la cultura en Pierre Bourdieu. Revista Colombiana de Sociología. 7(1), 9-26.

Blanco Suárez, J. (2009). Educación superior, crédito educativo y equidad en Colombia 1992-2011. Revista Diálogos de Saberes 40: 139-155.

Blanco Suárez, J. (2009). Educación superior, crédito educativo y equidad en Colombia 19922011. Revista Diálogos de Saberes 40: 139-155.

Bocanegra Acosta, H. (2015). Sindicalismo, democracia y política pública. El caso del sector educativo colombiano. Bogotá: Universidad Libre. 
Bonilla Mejía L. (abril 2011). Doble jornada escolar y calidad de la educación en Colombia. Cartagena de Indias: Banco de la República - Centro de Estudios Económicos Regionales (CEER).

Colombia. Congreso de la República. (1945). Ley 43 de 1945 (diciembre 17). Por la cual se crea el Escalafón Nacional de Enseñanza Secundaria. Diario oficial. Año. LXXXII nro. 26014.

Colombia. Congreso de la República. (1947). Ley 64 de 1947 (diciembre 23). Por la cual se aumentan las pensiones de jubilación de los maestros de escuela primaria oficial y se reforma el artículo 5. ${ }^{\circ}$ de la Ley 43 de 1945. Diario Oficial 26619, p. 5.

Colombia. Defensoría del Pueblo. (2003). El Derecho a la Educación, serie DESC. Bogotá D. C.

Colombia. Ministerio de Educación Nacional. (2013). Estado del arte de experiencias relacionadas con la implementación de la jornada única en establecimientos educativos del sector rural y recomendaciones para la construcción de políticas públicas en Colombia: Informe de resultados. Viceministerio de Educación Preescolar, Básica y Media. Programa de Fortalecimiento de la Cobertura con Calidad para el Sector Educativo Rural Fase II. Magdalena Arango Vallejo, contrato nro. 135. Bogotá D. C.

Colombia. Ministerio de Educación Nacional. (2017). Audiencia Pública de Rendición de Cuentas 2016. 20 de abril. Disponible en https://www.mineducacion. gov.co/1759/w3-article-360451.html?_noredirect=1

Colombia. Ministerio de Educación Nacional. (15 de septiembre de 2017). «Debemos pensar en una jornada única pertinente a las condiciones de cada territorio», ministra de Educación (E) Constanza Alarcón.. Disponible en https://www. mineducacion.gov.co/1759/w3-article-376560.html?_noredirect=1.

Colombia. Ministerio de Educación Nacional. (2018). Lineamientos para la implementación de la jornada única en Colombia 2018. Bogotá: MEN. Disponible en https://www.mineducacion.gov.co/1759/articles-367130_recurso.pdf

Colombia. Presidencia de la República. (1946). Decreto 1487 de 1946 (mayo 14). Por el cual se reglamenta la Ley 43 de 1945, sobre Escalafón de Profesores de Enseñanza Secundaria.

Colombia. Presidencia de la República. (1948). Decreto 30 de 1948 (enero 12). Por el cual se reglamenta el artículo $7 .^{\circ}$ de la Ley 64 de 1947 y se reforma el Decreto número 1487 de 1946. Diario Oficial 26638. 
Colombia. Presidencia de la República. (1967). Decreto 0155 de 1967 (febrero 4). Por el cual se autoriza el funcionamiento de planteles de doble jornada, se fijan derechos de matrícula y pensión de estudios, y se dictan otras disposiciones. Diario oficial 32152.

Colombia. Presidencia de la República. (2017). Decreto 2105 de 2017 (diciembre 14). Por el cual se modifica parcialmente el Decreto 1075 de 2015, Único Reglamentario del Sector Educación, en relación con la jornada única escolar, los tipos de cargos del sistema especial de carrera docente y su forma de provisión, los concursos docentes y la actividad laboral docente en el servicio educativo de los niveles de preescolar, básica y media.

Colombia. Presidencia de la República. (19 de septiembre 2018). Declaración del presidente Iván Duque sobre el nuevo Programa de Alimentación Escolar (PAE).. Disponible en https://id.presidencia.gov.co/Paginas/prensa/2018/180919Declaracion-del-Presidente-Ivan-Duque-sobre-el-nuevo-Programa-de-Alimen tacion-Escolar-PAE.aspx

Connors M. C., \& Morris A. (2014). Comparing state policy approaches to early care and education quality: A multidimensional assessment of quality rating and improvement systems and child care licensing regulations. Early Childhood Research Quarterly.

D’Angelo L. A., \& Fernández D. (2012). Clima, conflictos y violencia en la escuela. Buenos Aires, Argentina: Fondo de las Naciones Unidas para la Infancia (UNICEF) Facultad Latinoamericana de Ciencias Sociales (FLACSO).

El Espectador. (27 de agosto de 2018). La implementación de la jornada única se hará de manera gradual, seria y con sentido. Disponible en https:/ / www.elespectador. $\mathrm{com} /$ noticias/educacion/la-implementacion-de-la-jornada-unica-se-hara-demanera-gradual-seria-y-con-sentido-explico-la-articulo-808629.

El Tiempo. Com. (2017). Ministerio de Educación rindió cuentas. Yaneth Giha, acompañada de otros funcionarios, presentó cifras, resultados y proyectos de 2016. Disponible en https:/ / www.eltiempo.com/vida/educacion/rendicion-de-cuentas-del-ministerio-de-educacion-nacional-79810.

Federación Colombiana de Trabajadores de la Educación (Fecode). (2017). Circular nro. 38: Desarrollo de la encuesta para las condiciones de implementación de la jornada única. Disponible en https:/ / fecode.edu.co/images/CircularesPDF/circulares_2017/CIRCULAR_No._38.pdf.

Fundación Compartir. (2013). Tras la excelencia docente: ¿Cómo mejorar la calidad de la educación de todos los colombianos? Equivalentes, Compartir por la equidad y Compartir para vivir mejor. Bogotá: Fundación Compartir. 
Gallego Betancourth, M. L. (2008). Investigación evaluativa del programa jornada escolar complementaria ejecutada por la Caja de Compensación Familiar de Caldas. Centro de Estudios Avanzados en Niñez y Juventud alianza de la Universidad de Manizales y el CINDE.

Helg, A. (1987). La educación en Colombia 1918-1957. Una historia económica y política. Bogotá: Fondo Editorial CEREC.

Holland, P. (2012). América Latina: ¿es muy corta la jornada escolar? América Latina y el caribe Oportunidad para todos. Banco Mundial- BIRF. Disponible en http:/ / blogs.worldbank.org/latinamerica/es/am-rica-latina-es-muy-corta-la-jornadaescolar.

Lenis Mejía J. D. (2017). Factores que tienen en crisis a la educación en Colombia. Disponible en https://www.las2orillas.co/factores-tienen-crisis-la-educacioncolombia

Martinic, S. (2015). El tiempo y el aprendizaje escolar, la experiencia de la extensión de la jornada escolar en Chile. Revista Brasileira de Educação, 20 (61), abril-junio, 479499.

Miñana Blasco, C. (2008). «Tiempo para el aprendizaje»: reformas educativas en Colombia y reconfiguración espacio-temporal de las escuelas. Propuesta Educativa, 29, junio. Facultad Latinoamericana de Ciencias Sociales. Buenos Aires, Argentina.

Muñoz Villalobos V. (2011). El derecho a la educación: una mirada comparativa Argentina, Uruguay, Chile y Finlandia. UNESCO. Oficina Regional de Educación para América latina y el Caribe. Santiago de Chile.

Organización de Naciones Unidas (ONU). Asamblea General, 1966. Resolución 2200 A (XXI), 16 de diciembre. Observación general nro. 13: El derecho a la educación (artículo 13).

Pardo Romero, M. A. (1 de julio de 2018). Informe Distrital, Segunda Parte. Disponible en http:/ / www.adebogota.org/index.php/actualidad/informe-al-magisterio-2parte/7893-informe-distrital-2-parte-miguel-angel-pardo-1-de-julio-de-2018

Parsons W. (2009). Políticas públicas. Una introducción a la teoría y la práctica del análisis de políticas públicas. México D. F.: Facultad Latinoamericana de Ciencias Sociales, sede México (FLACSO)/Miño y Dávila Editores.

Pérez Dávila, F. L. (2018). Políticas educativas en Colombia: en busca de la calidad. Actualidades Pedagógicas, (71), 193-213. DOI: http:/ / dx.doi.org/10 
Quintero-Corzo, J.; Munévar-Molina R. A., \& Munévar-Quintero F. I. (2015). Ambientes escolares saludables. Revista Salud Pública. 17(2): 229-241. DOI: http:// dx.doi.org/10.15446/rsap.v17n2.35882

Restrepo, J. J. (6 de febrero de 2018). Decreto 2105 que modifica la jornada única no fue aprobado por Fecode. Unión Sindical de Directivos Docentes del Departamento de Antioquia (USDIDEA). Disponible en http:/ / www.usdidea.org.co/index.php/ institucional/126-dependencias/prensa-y-propaganda/705-decreto-2105-quemodifica-la-jornada-unica-los-tipos-de-cargo-de-carrera-y-su-forma-de-provisionno-fue-aprobado-por-fecode

Rivas C. (31 de mayo de 2017). Entrevista Noticias Caracol.. Disponible en https:/ / noticias.caracoltv.com/colombia/cuanto-se-gana-un-profe-en-colombia-estas-sonlas-razones-del-paro-segun-presidente-de-fecode.

Roth Deubel, A. N. (2004). Políticas públicas. Bogotá D. C: Ediciones Aurora.

Unesco. (9 de octubre de 1998). Declaración mundial sobre la educación superior en el siglo XXI: visión y acción y marco de acción prioritaria para el cambio y el desarrollo de la educación superior. Disponible en http:/ / www.unesco.org/education/ educprog/wche/declaration_spa.htm

Unesco. (2000). Programa Educación para Todos. Foro Consultivo Internacional sobre educación para Todos. Dakar Senegal, 26-28 de abril. Disponible en http: //www.eclac.org/cumbres/getProd.asp?xml=/cumbres/8/18/P18.xml\&xsl= /cumbres/phistoriaf.xsl.

Zamora Siervo, C. (2014). Efecto de la jornada escolar completa sobre la calidad laboral en Chile. Universidad Adolfo Ibáñez. Disponible en https:/ / editorialexpress. com/cgi-bin/conference/download.cgi?db_name=SECHI2014\&paper_id=91 


\author{
ANEXO \\ UNIVERSIDAD ANTONIO NARIÑO \\ PROGRAMA DE MAESTRÍA EN EDUCACIÓN \\ PROYECTO DE INVESTIGACIÓN LA JORNADA ÚNICA ESCOLAR \\ EN BOGOTÁ: LA EXPERIENCIA DE UNA INSTITUCIONES \\ DE EDUCACIÓN DISTRITALE (IED)
}

Folio:

Entrevistador/a:

Fecha: /

A continuación encontrará una serie de preguntas destinadas a conocer su opinión sobre diversos aspectos de la Jornada Única que se implementa en su colegio. Muy importante conocer su percepción sobre las condiciones en que se ha desarrollado esta experiencia y los procesos académicos y convivenciales que con ella se han generado dentro del colegio.

En el cuestionario se consideran dos temas significativos para el colegio: el primero referido a los aspectos curriculares y el segundo relacionado con la convivencia escolar. Cada una de estas partes está dividida en unos subtemas.

Por favor, lea las preguntas y conteste la alternativa que más se acerca a lo que usted piensa. Sus respuestas son confidenciales y serán reunidas junto a las respuestas de otros miembros de la comunidad educativa de la institución

Muy agradecidos por colaboración.

\title{
PRIMERA PARTE: ASPECTOS CURRICULARES
}

¿Qué calificación le daría a los siguientes aspectos del colegio en el marco de implementación de la jornada única? Considerando la respectiva escala de 1 a 5 , en donde 1 es deficiente, 2 es regular, 3 es aceptable, 4 es bueno y 5 es excelente.

Por favor, marcar con una X la alternativa con la que esté de acuerdo. 


\begin{tabular}{|c|c|c|c|c|c|}
\hline \multirow{2}{*}{$\begin{array}{l}\text { 1.1. Subtema: Organización } \\
\text { curricular }\end{array}$} & \multicolumn{5}{|c|}{ Escala } \\
\hline & Deficiente & Regular & Aceptable & Bueno & Excelente \\
\hline $\begin{array}{l}\text { 101. Transformaciones } \\
\text { pedagógicas, nuevas } \\
\text { áreas o proyectos } \\
\text { pedagógicos }\end{array}$ & 1 & 2 & 3 & 4 & 5 \\
\hline 102. Plan de estudios. & 1 & 2 & 3 & 4 & 5 \\
\hline $\begin{array}{l}\text { 103. Prevención del fracaso } \\
\text { escolar y la } \\
\text { reprobación. }\end{array}$ & 1 & 2 & 3 & 4 & 5 \\
\hline $\begin{array}{l}\text { 104. Orientación } \\
\text { vocacional y } \\
\text { profesional. }\end{array}$ & 1 & 2 & 3 & 4 & 5 \\
\hline $\begin{array}{l}\text { 105. Proyecto de } \\
\text { dirección de curso. }\end{array}$ & 1 & 2 & 3 & 4 & 5 \\
\hline $\begin{array}{l}\text { 106. Diálogo con los } \\
\text { padres y oportunidad } \\
\text { en la entrega de } \\
\text { informes académicos. }\end{array}$ & 1 & 2 & 3 & 4 & 5 \\
\hline $\begin{array}{l}\text { 107. Funcionamiento de } \\
\text { Consejo Académico y } \\
\text { Comités de } \\
\text { evaluación y } \\
\text { promoción. }\end{array}$ & 1 & 2 & 3 & 4 & 5 \\
\hline
\end{tabular}

\begin{tabular}{|c|c|c|c|c|c|}
\hline \multirow{2}{*}{$\begin{array}{l}\text { 1.2. Subtema: } \\
\text { Infraestructura e insumos }\end{array}$} & \multicolumn{5}{|c|}{ Escala } \\
\hline & Deficiente & Regular & Aceptable & Bueno & Excelente \\
\hline $\begin{array}{l}\text { 108. Disposición del nú- } \\
\text { mero de aulas nece- } \\
\text { sarias. }\end{array}$ & 1 & 2 & 3 & 4 & 5 \\
\hline $\begin{array}{l}\text { 109. Disposición y uso del } \\
\text { espacio al aire libre o } \\
\text { deportivos: número y } \\
\text { tipo de escenarios } \\
\text { para la práctica } \\
\text { deportiva. }\end{array}$ & 1 & 2 & 3 & 4 & 5 \\
\hline $\begin{array}{l}\text { 110. Disposición y uso de } \\
\text { recursos tecnológicos, } \\
\text { informáticos, } \\
\text { audiovisuales. }\end{array}$ & 1 & 2 & 3 & 4 & 5 \\
\hline $\begin{array}{l}\text { 111. Disposición de } \\
\text { materiales o insumos } \\
\text { para actividades } \\
\text { académicas: } \\
\text { marcadores, } \\
\text { papelería, balones. }\end{array}$ & 1 & 2 & 3 & 4 & 5 \\
\hline
\end{tabular}




\begin{tabular}{l|l|l|l|l|l}
\hline $\begin{array}{l}\text { 112. } \\
\text { Disposición de aulas } \\
\text { especializadas: } \\
\text { laboratorios, } \\
\text { informática, } \\
\text { bilingüismo, diseño. }\end{array}$ & 1 & 2 & 3 & 4 & 5 \\
\hline $\begin{array}{l}\text { 113. Disposición de aulas } \\
\text { especializadas: } \\
\text { gimnasio, de danzas, } \\
\text { de música, de artes } \\
\text { plásticas. }\end{array}$ & 1 & 2 & 3 & 4 & 5 \\
\hline
\end{tabular}

\begin{tabular}{l|c|c|c|c|c}
\hline $\begin{array}{l}\text { 1.3. Subtema: procesos } \\
\text { docentes }\end{array}$ & Deficiente & Regular & Aceptable & Bueno & Excelente \\
\hline $\begin{array}{c}\text { 114. Utilidad de la } \\
\text { evaluación docente. }\end{array}$ & 1 & 2 & 3 & 4 & 5 \\
\hline $\begin{array}{c}\text { 115. Planes de } \\
\text { mejoramiento docente. }\end{array}$ & 1 & 2 & 3 & 4 & 5 \\
\hline $\begin{array}{c}\text { 116. Seguimiento y control } \\
\text { académico y asistencia. }\end{array}$ & 1 & 2 & 3 & 4 & 5 \\
\hline $\begin{array}{c}\text { 117. Programas de } \\
\text { actualización y } \\
\text { formación docente. }\end{array}$ & 1 & 2 & 3 & 4 & 5 \\
\hline $\begin{array}{c}\text { 118. Participación docente } \\
\text { en la organización } \\
\text { académica }\end{array}$ & 1 & 2 & 3 & 4 & 5 \\
\hline
\end{tabular}

\begin{tabular}{l|c|c|c|c|c}
\hline \multirow{2}{*}{$\begin{array}{l}\text { 1.4. Subtema: Tiempo y } \\
\text { parámetros }\end{array}$} & Deficiente & Regular & Aceptable & Bueno & Excelente \\
\hline $\begin{array}{l}\text { 119. Uso del tiempo } \\
\text { adicional y } \\
\text { cumplimiento de } \\
\text { horario según criterios. }\end{array}$ & 1 & 2 & 3 & 4 & 5 \\
\hline $\begin{array}{l}\text { 120. Número de estudiantes } \\
\text { por aula. }\end{array}$ & 1 & 2 & 3 & 4 & 5 \\
\hline $\begin{array}{l}\text { 121. Número de docentes } \\
\text { según necesidades } \\
\text { institucionales. }\end{array}$ & 1 & 2 & 3 & 4 & 5 \\
\hline $\begin{array}{l}\text { 122. Control de asistencia y } \\
\text { permanecía de } \\
\text { docentes. }\end{array}$ & 1 & 2 & 3 & 4 & 5 \\
\hline $\begin{array}{l}\text { 123. Control de asistencia } \\
\text { de estudiantes a } \\
\text { jornada y clases. }\end{array}$ & 1 & 2 & 3 & 4 & 5 \\
\hline
\end{tabular}




\section{SEGUNDA PARTE: ASPECTOS CONVIVENCIALES}

¿Qué calificación le daría a los siguientes aspectos relacionados con las condiciones convivenciales del colegio en el marco de implementación de la jornada única? Considerando la respectiva escala de 1 a 5 , en donde 1 es deficiente, 2 es regular, 3 es aceptable, 4 es bueno y 5 es excelente.

Por favor, marcar con una $\mathrm{X}$ la alternativa con la que esté de acuerdo.

\begin{tabular}{|c|c|c|c|c|c|}
\hline \multirow{2}{*}{$\begin{array}{l}\text { 2.1. Subtema: Gobierno } \\
\text { escolar, participación y toma } \\
\text { de decisiones. }\end{array}$} & \multicolumn{5}{|c|}{ Escala } \\
\hline & Deficiente & Regular & Aceptable & Bueno & Excelente \\
\hline $\begin{array}{l}\text { 124. Funcionamiento del } \\
\text { gobierno escolar y } \\
\text { proceso de toma de } \\
\text { decisiones. }\end{array}$ & 1 & 2 & 3 & 4 & 5 \\
\hline $\begin{array}{l}\text { 125. Funcionamiento del } \\
\text { Comité Institucional de } \\
\text { Convivencia. }\end{array}$ & 1 & 2 & 3 & 4 & 5 \\
\hline $\begin{array}{l}\text { 126. Proyecto de convivencia } \\
\text { y formación ciudadana. }\end{array}$ & 1 & 2 & 3 & 4 & 5 \\
\hline $\begin{array}{l}\text { 127. Participación de los } \\
\text { padres en procesos de } \\
\text { acompañamiento y } \\
\text { orientación convivencial. }\end{array}$ & 1 & 2 & 3 & 4 & 5 \\
\hline $\begin{array}{l}\text { 128. Convenios } \\
\text { interinstitucionales para } \\
\text { el acompañamiento, } \\
\text { asesoría, consultoría o } \\
\text { apoyo convivencial. }\end{array}$ & 1 & 2 & 3 & 4 & 5 \\
\hline $\begin{array}{l}\text { 129. Procesos de mediación y } \\
\text { conciliación. }\end{array}$ & 1 & 2 & 3 & 4 & 5 \\
\hline
\end{tabular}




\begin{tabular}{|c|c|c|c|c|c|}
\hline \multirow{2}{*}{$\begin{array}{l}\text { 2.2. Subtema: Normatividad } \\
\text { y Ruta de atención Integral a } \\
\text { la Convivencia Escolar. }\end{array}$} & \multicolumn{5}{|c|}{ Escala } \\
\hline & Deficiente & Regular & Aceptable & Bueno & Excelente \\
\hline $\begin{array}{l}\text { 130. Manual de Convivencia } \\
\text { y Ruta de Atención In- } \\
\text { tegral a la Convivencia } \\
\text { Escolar conforme a la } \\
\text { Ley } 1620 \text { de } 2013 \text { y el } \\
\text { Decreto } 1965 \text { de } 2013 \text {. }\end{array}$ & 1 & 2 & 3 & 4 & 5 \\
\hline $\begin{array}{l}\text { 131. Seguimiento al debido } \\
\text { proceso y conducto } \\
\text { regular. }\end{array}$ & 1 & 2 & 3 & 4 & 5 \\
\hline $\begin{array}{l}\text { 132. Atención a la violencia } \\
\text { escolar, violencia en la } \\
\text { escuela y violencia } \\
\text { contra la escuela. }\end{array}$ & 1 & 2 & 3 & 4 & 5 \\
\hline $\begin{array}{l}\text { 133. Autoevaluación } \\
\text { convivencial de los } \\
\text { escolares. }\end{array}$ & 1 & 2 & 3 & 4 & 5 \\
\hline $\begin{array}{l}\text { 134. Periodicidad de reunio- } \\
\text { nes de docentes o equi- } \\
\text { pos docentes para aná- } \\
\text { lisis de problemática } \\
\text { convivencial y retroali- } \\
\text { mentación de procesos } \\
\text { convivenciales. }\end{array}$ & 1 & 2 & 3 & 4 & 5 \\
\hline $\begin{array}{ll}\text { 135. } & \text { Seguimiento } \\
\text { convivencial con } \\
\text { acudientes. }\end{array}$ & 1 & 2 & 3 & 4 & 5 \\
\hline $\begin{array}{l}\text { 136. Promoción de los } \\
\text { derechos humanos. }\end{array}$ & 1 & 2 & 3 & 4 & 5 \\
\hline
\end{tabular}

\begin{tabular}{l|c|c|c|c|c}
\hline 2.3. Subtema: Seguridad y & \multicolumn{5}{|c}{ Escala } \\
\cline { 2 - 6 } convivencia escolar & Deficiente & Regular & Aceptable & Bueno & Excelente \\
\hline $\begin{array}{l}\text { 137. Vigilancia y seguridad } \\
\text { interna. }\end{array}$ & 1 & 2 & 3 & 4 & 5 \\
\hline $\begin{array}{l}\text { 138. Seguridad de los entor- } \\
\text { nos escolares. }\end{array}$ & 1 & 2 & 3 & 4 & 5 \\
\hline 139. Clima laboral. & 1 & 2 & 3 & 4 & 5 \\
\hline 140. Apoyo de otras & 1 & 2 & 3 & 4 & 5 \\
$\begin{array}{l}\text { autoridades } \\
\text { competentes: ICBF, } \\
\text { Policía, Comisaría de } \\
\text { Familia, Hospital. }\end{array}$ & 1 & 2 & 3 & 4 & 5 \\
\hline $\begin{array}{l}\text { 141. Asesoramiento y } \\
\text { seguimiento del nivel } \\
\text { central. }\end{array}$ & & & & & \\
\hline
\end{tabular}




\begin{tabular}{l|c|c|c|c|c}
\hline \multirow{2}{*}{$\begin{array}{l}\text { 2.4. Subtema: Bienestar } \\
\text { estudiantil }\end{array}$} & \multicolumn{5}{|c}{ Escala } \\
\cline { 2 - 6 } & Deficiente & Regular & Aceptable & Bueno & Excelente \\
\hline $142 . \quad \begin{array}{l}\text { Plan de Alimentación } \\
\text { escolar }\end{array}$ & 1 & 2 & 3 & 4 & 5 \\
\hline $143 . \quad \begin{array}{l}\text { Prevención, atención } \\
\text { y seguimiento de } \\
\text { consumo de SPA. }\end{array}$ & 1 & 2 & 3 & 4 & 5 \\
\hline $144 . \quad \begin{array}{l}\text { Prevención del } \\
\text { embarazo } \\
\text { adolescente. }\end{array}$ & 1 & 2 & 3 & 4 & 5 \\
\hline $\begin{array}{l}\text { Servicio de } \\
\text { orientación y } \\
\text { consejería escolar. }\end{array}$ & 1 & 2 & 3 & 4 & 5 \\
\hline
\end{tabular}

